\title{
The Adult Ventricular-Subventricular Zone (V-SVZ) and Olfactory Bulb (OB) Neurogenesis
}

\author{
Daniel A. Lim and Arturo Alvarez-Buylla \\ Eli and Edythe Broad Center of Regeneration Medicine and Stem Cell Research at UCSF, Department \\ of Neurological Surgery, University of California, San Francisco, California 94143 \\ Correspondence: daniel.lim@ucsf.edu; abuylla@stemcell.ucsf.edu
}

\begin{abstract}
A large population of neural stem/precursor cells (NSCs) persists in the ventricular-subventricular zone (V-SVZ) located in the walls of the lateral brain ventricles. V-SVZ NSCs produce large numbers of neuroblasts that migrate a long distance into the olfactory bulb (OB) where they differentiate into local circuit interneurons. Here, we review a broad range of discoveries that have emerged from studies of postnatal V-SVZ neurogenesis: the identification of NSCs as a subpopulation of astroglial cells, the neurogenic lineage, new mechanisms of neuronal migration, and molecular regulators of precursor cell proliferation and migration. It has also become evident that V-SVZ NSCs are regionally heterogeneous, with NSCs located in different regions of the ventricle wall generating distinct $\mathrm{OB}$ interneuron subtypes. Insights into the developmental origins and molecular mechanisms that underlie the regional specification of V-SVZ NSCs have also begun to emerge. Other recent studies have revealed new cellintrinsic molecular mechanisms that enable lifelong neurogenesis in the V-SVZ. Finally, we discuss intriguing differences between the rodent $\mathrm{V}-\mathrm{SVZ}$ and the corresponding human brain region. The rapidly expanding cellular and molecular knowledge of V-SVZ NSC biology provides key insights into postnatal neural development, the origin of brain tumors, and may inform the development regenerative therapies from cultured and endogenous human neural precursors.
\end{abstract}

No ew neurons continue to be added throughout life to the olfactory bulb (OB) in the brain of many mammals. In rodents, the adult germinal region for $\mathrm{OB}$ neurogenesis is located along the walls of the brain lateral ventricles. Recent results regarding the spatial arrangement and cellular morphology of the primary neural precursors-or, neural stem cells (NSCs) - indicate that this region has characteristics similar to both the embryonic ventricular zone (VZ) and subventricular zone (SVZ). Given this new understanding, we now refer to this region as the ventricular-subventricular zone (V-SVZ).

Neuroblasts born from NSCs in the mouse $\mathrm{V}-\mathrm{SVZ}$ migrate rostrally into the $\mathrm{OB}$ where they then disperse radially and differentiate into functional interneurons (Fig. 1). Several distinct interneuron subtypes are generated by the V-SVZ, and estimates indicate that thousands of new $\mathrm{OB}$ neurons are generated every day in the young adult rodent brain. The adult $\mathrm{V}-\mathrm{SVZ}$ is also the birthplace of oligodendro-

Editors: Fred H. Gage, Gerd Kempermann, and Hongjun Song

Additional Perspectives on Neurogenesis available at www.cshperspectives.org

Copyright (C) 2016 Cold Spring Harbor Laboratory Press; all rights reserved; doi: 10.1101/cshperspect.a018820

Cite this article as Cold Spring Harb Perspect Biol 2016;8:a018820 
D.A. Lim and A. Alvarez-Buylla

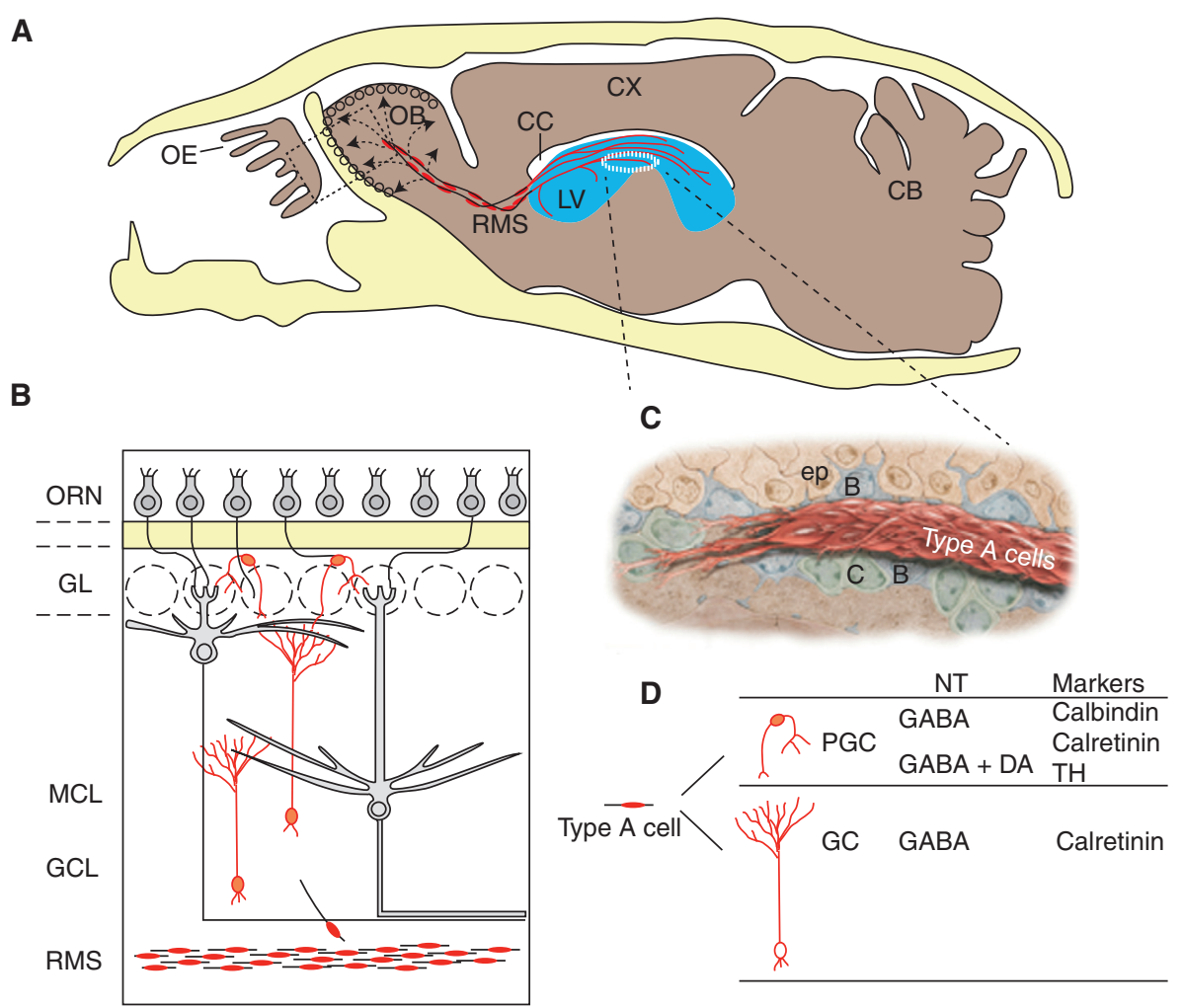

Figure 1. Overview of adult mouse olfactory bulb $(\mathrm{OB})$ neurogenesis from the ventricular-subventricular zone (V-SVZ). (A) Sagittal section through mouse head (calvarium is yellow). Neuroblasts (type A cells) born in the $\mathrm{V}-\mathrm{SVZ}$ of the lateral ventricle (blue) migrate through a network of paths (red) into the rostral migratory stream (RMS), which enters the OB. Cells then leave the RMS (arrows, dashed lines) and migrate radially into the OB. Boxed area is shown enlarged in $B$. $(B)$ Neuronal layers of OB. Migratory cells depart the RMS and differentiate into granule cells (GC) or periglomerular cells (PGC), which reside in the granule cell layer (GCL) and glomerular layer (GL), respectively (type A cells and differentiated interneurons are red). ORNs (small gray cells) in the olfactory epithelium (OE) project to the GL. The main projection neurons of the OB (mitral cells and tufted cells) are in gray. $(C)$ Artists' rendition of a chain of migratory type A cells. These chains are ensheathed by glial cells (type B cells, blue) and are associated with clusters of transit-amplifying cells (type C cells, green). (D) Diversity of OB interneurons. Type A cells differentiate into either PGCs or GCs, which can be distinguished by morphology, neurotransmitter (NT) phenotype, and markers. CC, Corpus callosum; Cx, cortex; CB, cerebellum; ORN, olfactory receptor neuron; MCL, mitral cell layer; ep, ependymal cell; TH, tyrosine hydroxylase.

cytes in both normal and diseased brain. In contrast to the embryonic brain, wherein neural precursors are continually changing their developmental potential, the adult brain V-SVZ and its resident NSCs are relatively stable, generating new neurons and glia for the life of the animal. V-SVZ NSCs can be cultured as monolayers, recapitulating in vitro key aspects of in vivo neurogenesis, and generate $\mathrm{OB}$ interneurons when transplanted back to the SVZ in vivo.
The well-characterized V-SVZ region, the relatively simple developmental lineages of adult $\mathrm{V}$ SVZ NSCs, and the ability to robustly culture these NSCs for molecular and biochemical studies have made the V-SVZ particularly tractable for anatomical, cell biological, and molecular-genetic studies of NSC regulation and other fundamental aspects of neural development.

Here, we will first review basic anatomical, cellular, and molecular aspects of the rodent 
V-SVZ NSC niche. We will then incorporate our growing understanding of the cell-intrinsic molecular mechanisms that regulate V-SVZ NSCs, including the role of transcription factors and epigenetic regulators, such as chromatin-modifying factors and noncoding RNAs. Finally, we will review emerging results that highlight intriguing differences between the rodent and human SVZ. Taken together, the cellular and molecular knowledge of V-SVZ NSCs biology and our growing understanding of this region in the human brain provide key insights into postnatal neural development as well as specific disease states, such as glial brain tumors. Furthermore, lessons learned from the rodent V-SVZ could serve to develop general strategies for the manipulation of cultured human NSCs as well as endogenous neural precursors for the purpose of regenerative therapies.

\section{THE CELLULAR ARCHITECTURE OF THE V-SVZ}

\section{V-SVZ Progenitors and Lineages for Adult Neurogenesis}

The mammalian brain contains ventricles filled with cerebrospinal fluid (CSF), and in adult mice, several thousand NSCs are distributed along the lateral ventricle walls (Mirzadeh et al. 2008; Ponti et al. 2013). These adult V-SVZ NSCs, called type B1 cells, have many characteristics of brain astrocytes (Doetsch et al. 1997, 1999a; Garcia-Verdugo et al. 1998), a glial celltype known to have various support functions for the brain. Type B1 cells express a number of glial markers including the glial-fibrillary acidic protein (GFAP), glutamate aspartate transporter (GLAST), and brain lipid-binding protein (BLBP). Furthermore, type B1 cells have endfeet on blood vessels, which is typical of gray matter astrocytes. As we discuss in sections below, type B1 cells are unique among brain astrocytes in that they frequently make direct contact with the brain ventricle.

Type B1 cells can exist in a quiescent or activated state (Codega et al. 2014; Mich et al. 2014). Nestin is an intermediate filament protein that has generally been considered to be a marker of NSCs. Although quiescent type B1 cells do not express nestin, the "activated" population of B1 cells does express this protein. Thus, these recent data suggest that some methods of lineage tracing based on the expression of the Nestin locus may not fully reflect the developmental potential of quiescent NSCs in the V-SVZ.

Activated type B1 cells give rise to transitamplifying precursors (type $\mathrm{C}$ cells), which generate neuroblasts (type A cells) that migrate to the OB. The transcription factors Ascl1 (also known as Mash1) and Dlx2 are frequently used as markers of type $\mathrm{C}$ cells. The expression of doublecortin (DCX) and polysialylated neural-cell-adhesion molecule (PSA-NCAM) distinguish Dlx2-positive type A cells from type C cells (Doetsch et al. 1997).

Based on in vitro time-lapse video microscopy, V-SVZ NSCs can undergo asymmetric division for self-renewal and the production of type C cells (Ortega et al. 2013a,b). In vivo analysis of cell proliferation by mitotic marker incorporation indicates that type $\mathrm{C}$ cells then divide symmetrically approximately three times before becoming type A cells, which divide one, possibly two, more times while en route to the OB (Ponti et al. 2013). Type A cells move along one another within elongated cellular aggregates called chains, which are ensheathed by GFAPpositive cells (Lois 1996; Lois et al. 1996; Wichterle et al. 1997). This neuroblast chain migration occurs within a network of interconnecting paths that converge, forming the rostral migratory stream (RMS) at the anterior SVZ (Doetsch and Alvarez-Buylla 1996). The RMS carries the type A cells into the OB where they then migrate radially outward from the RMS and differentiate into interneurons.

Type B1 cells also give rise to glial lineages, including oligodendrocytes and nonneurogenic astrocytes. As compared with $\mathrm{OB}$ neurogenesis, the V-SVZ generates relatively few oligodendrocytes in adulthood. In normal, uninjured mice, type B1 cells generate new oligodendrocytes for the corpus callosum (Menn et al. 2006). After demyelinating injury, V-SVZ oligodendrogliogenesis increases, suggesting that type $\mathrm{B} 1$ cells can respond to changes in- 
duced by injury or disease states (Nait-Oumesmar et al. 1999; Picard-Riera et al. 2002). Brain injury has also been suggested to induce the V-SVZ to produce astrocytes that migrate to the injury site (Benner et al. 2013). Although V-SVZ NSCs have been found to be capable of producing neurons, astrocytes, and oligodendrocytes, this multipotent developmental potential has been most frequently observed in cultures that use higher concentrations of exogenous growth factors. Single GFAP-positive cells isolated from the V-SVZ by fluorescent activated cell sorting (FACS) can generate colonies that contain neuronal and glial lineages when cocultured on support astrocyte monolayers, further supporting that notion that V-SVZ NSCs are multipotent (Menn et al. 2006). In contrast, direct video time-lapse microscopy of neural precursors from the V-SVZ has not identified cells that generate both neuronal and glial lineages (Ortega et al. 2013b). Rather, such V-SVZ cells cultured individually on a glass substrate in growth factor-free media generate colonies that contain neurons or oligodendrocytes, but not both. It remains to be determined whether type B1 cells in vivo, or when presented with appropriate extrinsic niche signals, can generate both neuronal and glial lineages.

Type B1 Cells: A Specialized Astrocyte with Unique Ventricular Contact and Basal Extension

The lateral ventricle ependyma has been often described as a layer of multiciliated epithelial cells that form a tight barrier between the brain parenchyma and the ventricle lumen. However, light and electron microscopy (EM) show that the adult brain ventricular epithelium is not entirely composed of ependymal cells. In normal mice, type B1 cells make direct contact with the ventricle (Doetsch et al. 1999b, 2002; Conover et al. 2000; Mirzadeh et al. 2008); most type $\mathrm{B} 1$ cells contact the ventricle by extending a thin cellular process between ependymal cells. Thus, the boundary between the ependymal layer and the SVZ is blurred by this interdigitation of type $\mathrm{B}$ cells and ependyma. In coronal sections, without EM, it can be difficult to distinguish these cell types because they are both very close to the ventricle lumen. However, when the surface of the ventricle is viewed en face in whole mount preparations and immunohistochemistry (Mirzadeh et al. 2010), the thin apical processes of type $B 1$ cells can be more easily appreciated with whole-mount immunohistochemistry (Mirzadeh et al. 2008). Although ependymal cells each bear many large, motile cilia, the apical surface of type B1 cells has a single, nonmotile cilium that lacks a central pair of microtubules. Such apical processes, each having a primary cilium, tend to cluster together at the center of a rosette of ependymal cells in a repeating "pinwheel" pattern.

The integrity of the ependymal cell layer appears to be critical for the germinal function of the V-SVZ and neurogenesis from type B1 cells. ANKYRIN3, an adaptor protein that regulates the attachment of membrane proteins, such as $\mathrm{N}$-cadherin to the cytoskeleton, is found at the apicolateral junctions of ependymal cells (Paez-Gonzalez et al. 2011). Type B1 cells do not have such ANKYRIN3 cell-adhesion domains. Decreased ankyrin3 expression in adult V-SVZ results in ependymal layer disruption and reduced neuroblast generation, suggesting that adult neurogenesis requires a normal ependymal layer.

Although the role of the primary cilium and ventricular contact of type B1 cells is not yet well known, it is interesting to note that cilium with this $9+0$ microtubule arrangement and ventricular contact are also characteristic of embryonic neuroepithelial cells, radial glia, and adult avian brain neuronal precursors (Sotelo and Trujillo-Cenoz 1958; Stensaas and Stensaas 1968; Alvarez-Buylla et al. 1998). During neural tube development, the primary cilium is required for sonic hedgehog (Shh) signaling (Wong and Reiter 2008), and this cellular structure may also play a role in the transduction of other signaling molecules, raising the interesting possibility that apical contact of type B1 cells and its primary cilium with the CSF is a critical component to the regulation of adult neurogenesis. Indeed, insulin-like growth factor 2 (IGF-2) in the CSF has been shown to regulate the proliferation of type B1 cells 
(Lehtinen et al. 2011), supporting the notion that the CSF provides extrinsic regulatory cues to the V-SVZ niche. SHH, Wnts, retinoic acid (RA), and bone morphogenetic proteins (BMP) are all found in CSF (Huang et al. 2010; Lehtinen and Walsh 2011; Lehtinen et al. 2011), and these factors regulate V-SVZ neurogenesis. Surprisingly, ablation of primary cilia with genetic methods at even very early stages of brain development does not result in major developmental defects (Tong et al. 2014b). However, in the $\mathrm{V}$-SVZ, loss of primary cilia in the ventral region known to be regulated by $\mathrm{SHH}$, does inhibit $\mathrm{SHH}$ signaling, and neurogenesis from that restricted population of cells is decreased. The potential role of the primary cilium in other regions of the V-SVZ and in NSCs of the embryonic brain remains to be determined.

\section{The Search for Markers of Type B1 Cells}

Markers that clearly distinguish type B1 cells from other cell types have been elusive. For instance, GFAP is expressed by many nonneurogenic brain astrocytes outside of the V-SVZ. The CD133 cell-surface marker has been used to enrich for V-SVZ NSCs, but expression of CD133 in type B1 cells is variable and is also prominently expressed on ependymal cells (Coskun et al. 2008; Mirzadeh et al. 2008; Beckervordersandforth et al. 2010). LewisX (Lex)/ CD15/SSEA-1 is a cell-surface carbohydrate antigen that has also been found on V-SVZ NSCs, but this marker is also present on many nonGFAP-expressing cells and some type A cells (Capela and Temple 2002; Imura et al. 2006; Shen et al. 2008). The epidermal growth factor receptor (EGFR) is found on "activated" type B1 cells and type C cells (Pastrana et al. 2009). Similarly, GLAST is found in both type B1 cells and some type $\mathrm{C}$ cells. Although high levels of Id1 have been found in type B1 cells, this transcription factor is present at lower levels in type C cells (Nam and Benezra 2009). Similarly, Tailless $(T l x)$ is expressed in type B1 cells but is also expressed at high levels in type C cells (Shi et al. 2004). More recently, VCAM1 has been found to be expressed on the apical process of type B1 cells and shown to play a critical role in NSC maintenance (Kokovay et al. 2012). As in other stem-cell systems, it is possible that identification of the type B1 cells will require the use of multiple markers with attention to the expression level of each gene product. Given that long noncoding RNAs (lncRNAs) are generally more tissue and cell specific than mRNAs (Cabili et al. 2011; Ramos et al. 2013), future studies of lncRNAs may also identify novel markers that distinguish V-SVZ cell types.

The Radial Glial Origin of Type B1 Cells:

Persistence of a VZ-Like Cell into Adulthood

The glial cell identity and ventricular contact of type $\mathrm{B} 1$ cells is particularly intriguing when examined in the broader context of embryonic brain development. In the embryo, a specialized type of glia (radial glia) gives rise to both neurons and glia (Noctor et al. 2001; Campbell and Gotz 2002; Anthony et al. 2004; Kriegstein and Alvarez-Buylla 2009). The cell bodies of radial glia reside in the $\mathrm{VZ}$, maintain contact with the brain ventricle, and possess a primary cilium at this apical surface. Radial glia selectively labeled at early postnatal ages give rise to type B1 cells, and some of these persist throughout life (Merkle et al. 2004). The ventricular contact of type B1 cells, their long-term neurogenic potential, and their unique apical process containing a primary cilium suggests the "persistence" of radial glial-like cells in what can be described as the adult VZ (Ihrie and Alvarez-Buylla 2011; Fuentealba et al. 2012).

Because of the "compressed" cellular arrangement in this adult germinal region, the ventricular and SVZ compartments are difficult to distinguish. We have, therefore, proposed that this region be referred to collectively as the V-SVZ, which can be subdivided into three domains based on the structure and spatial arrangement of type B1 cells (Fig. 2). Domain I (apical) contains the type B1 cells apical process and the body of ependymal cells; domain II (intermediate) contains the cell body of most type $\mathrm{B} 1$ cells, which are in contact with the type C and A cells; and domain III (basal) contains the B1 cell's basal process with end-feet on blood vessels. These subdomains may play a role 
D.A. Lim and A. Alvarez-Buylla

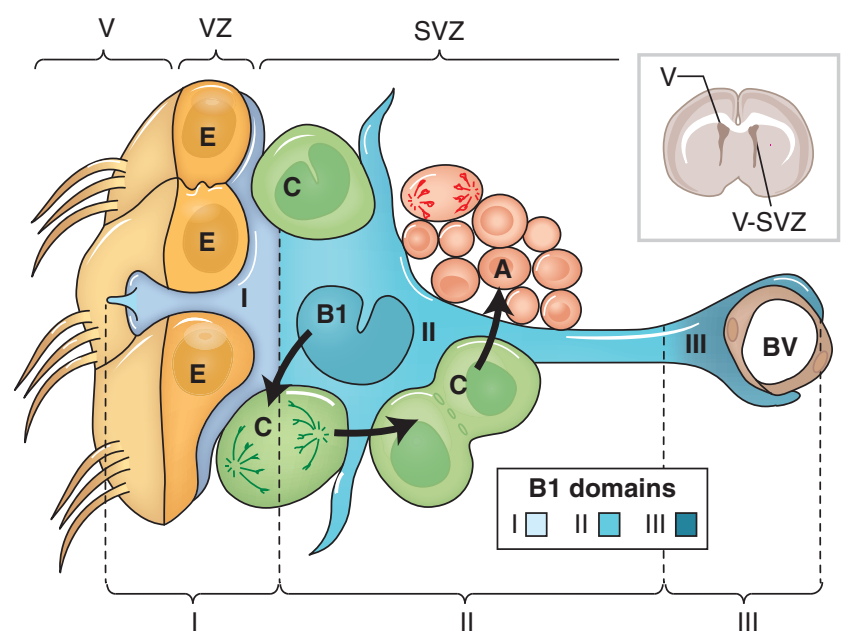

Figure 2. Cellular composition of the ventricular-subventricular zone (V-SVZ). Coronal section of adult mouse brain is shown in the upper right. The V-SVZ region indicated by the black arrow is shown enlarged in the lower left. Type B1 cells (blue) are the astrocytes that serve as the V-SVZ stem cell. These can divide and produce type C cells (green), which are rapidly dividing, transit amplifying cells. Type $\mathrm{C}$ cells give rise to type A cells (red), the migratory neuroblasts. A blood vessel (BV, brown) is shown at the right. The apical surface of type B1 cells has a primary cilium and makes contact with the ventricle, which is at the left. These apical surfaces are found at the center of a "pinwheel" composed of multiciliated ependymal cells (yellow). The V-SVZ can be subdivided into three domains based on the structure and spatial arrangement of type B1 cells: Domain I (apical) contains the type B1 cells apical process and the body of ependymal cells; domain II (intermediate) contains the cell body of most type B1 cells, which are in contact with the type C and A cells; and domain III (basal) contains the B1 cell's basal process with end-feet on blood vessels (see text for details).

in the regulation of type B1 cells by providing these NSCs with distinct sets of extrinsic signals along their apicobasal extent.

The spatial and morphological similarities between type B1 cells and embryonic radial glia, and the direct lineage relationship between these populations of neural precursors, suggests that adult-type B1 cells "preserve" embryonic-like characteristics throughout adult life. The prevailing model suggested that radial glia transform, after they produce neurons and glia in the embryo, into B1 cells (Kriegstein and Alvarez-Buylla 2009). This simple view is challenged by a recent lineage tracing study that investigates the pedigree of adult $\mathrm{B} 1$ cells (Fuentealba et al. 2015). The new results show that postnatal B1 cells are indeed derived from embryonic NSCs that produce also neurons and glia for other forebrain regions (including cortex, striatum, and septum). However, pre-B1 cells appear to separate from other forebrain lineages during mid-fetal development. During this time, the majority of B1 cells undergoes division but then remain largely quiescent until reactivated during postnatal life. Consistent with this observation, another recent study suggests that B1 cells are derived from radial glia that decelerate their proliferation during this period when the pre-B1 cell lineage separates from other forebrain lineages (Furutachi et al. 2015). These new findings suggest that the lineage for postnatal NSCs is not linear, but bifurcates in the embryo. Cell-intrinsic neurogenic "competence" is likely maintained in this population of pre-B1 cells to allow cell-extrinsic signals, later in life, to induce their reactivation and generation of neurons.

\section{Type B1 Cells Are Intrinsically Distinct Based on Their Positional Identity}

Although type B1 cells are distributed throughout most of the walls of the lateral ventricles, their location determines the types of $\mathrm{OB}$ 
neurons (Merkle et al. 2007; Alvarez-Buylla et al. 2008). For instance, ventral NSCs produce deep granule neurons and calbindin-positive but not tyrosine hydroxylase (TH)-positive periglomerular cells (PGCs), whereas dorsal NSCs produce superficial granule cells and THpositive but not calbindin-positive PGCs. Results from heterotopic grafting of NSCs (e.g., ventral NSCs transplanted into the dorsal V-SVZ) suggest that the positional heterogeneity of these NSCs is in large part cell-intrinsic (i.e., ventrally derived NSCs grafted to the dorsal V-SVZ still produce calbindin-positive but not $\mathrm{TH}$-positive PGCs). Thus, type B1 cells are not a homogeneous population of adult NSCs, and it is likely that these precursor cells will have significant epigenetic differences based on their physical location. Curiously, this regional specification is already established in the embryo at very early stages of development (Fuentealba et al. 2015).

This new understanding of regional specification of adult NSCs explains why extensive tangential migration is required to take young neurons from unique sites of birth, where specified $\mathrm{B} 1$ cells reside, to their final destination in the OB. Remarkably, interneurons for the OB are not only derived from the lateral wall of the lateral ventricle, but some specific subtypes are derived from the dorsal wall facing the cortex (pallium) (Kohwi et al. 2007; Ventura and Goldman 2007), the medial wall facing the septum, and from within the RMS (Vergano-Vera et al. 2006; Merkle et al. 2007; Alonso et al. 2008). Therefore, OB interneurons are derived from a very extensive postnatal germinal layer that includes most major subdivisions of the telencephalon. It is likely that all of these subregions contribute unique combinations of transcription factors (see below) that result in the generation of a diversity of interneurons with unique structural and physiological properties tailored for integration into different OB circuits.

It remains unclear how many subregions exist in the V-SVZ and how many different types of $\mathrm{OB}$ interneurons are produced. Until recently, we knew that at least six different subtypes of $\mathrm{OB}$ interneurons are produced postnatally: three types of periglomerular interneurons and three of granule cells (for more details on these subtypes, see Fuentealba et al. 2012). Recent evidence has revealed a small number of four additional subtypes of $\mathrm{OB}$ interneurons that differentiate close to the mitral cell layer (Merkle et al. 2014). These new interneurons continue to be produced in postnatal and adult brain suggesting that they have unique functional contributions to the $\mathrm{OB}$ circuits. Interestingly, these four neuronal subtypes are derived from very restricted domains in the most anterioventral V-SVZ. These anterioventral subdomains express unique combinations of transcription factors, including $N k x 6.1$ and $Z i c$ family members. Therefore, the postnatal and adult $\mathrm{V}-\mathrm{SVZ}$ is divided into germinal parcels uniquely specialized for the production of distinct types of interneurons destined for a very distant location in the OB.

The V-SVZ Basal Lamina, Endothelia, Microglia, and Other Cellular Components of the Neurogenic Niche

An extensive vascular plexus invests itself throughout domains II and III of the V-SVZ. Mercier et al. (2002) used EM to describe the V-SVZ vasculature and the associated extravascular basal lamina (BL). Blood vessels that penetrate into the V-SVZ consist of endothelial cells, pericytes, fibroblasts, and macrophages. The extravascular BL, which is rich in laminin and collagen-1, interdigitates extensively with all V-SVZ cell types, and there are also many microglial cells in contact with the BL and other $\mathrm{V}-\mathrm{SVZ}$ cells. It is possible that the BL concentrates and/or modulate cytokines/growth factors derived from local cells, perhaps playing a role in the maintenance of type B1 cells and adult neurogenesis (Alvarez-Buylla and Lim 2004). Interestingly, as mentioned above, type B1 cells frequently contact endothelial cells via a specialized basal end-foot, and clusters of type B1 and C cells are associated with blood vessels that are more "leaky," as revealed by the injection of tracer molecules into the peripheral bloodstream (Tavazoie et al. 2008). Furthermore, clusters of actively dividing V-SVZ cells (likely type C) are concentrated next to blood 
D.A. Lim and A. Alvarez-Buylla

vessels. This anatomical arrangement and other experimental data discussed later indicate that blood-derived factors regulate V-SVZ neurogenesis.

Endothelial and microglial cells in the VSVZ secrete factors that are important for the V-SVZ niche. Endothelial cells cocultured with V-SVZ explants enhance neuroblast migration and maturation (Leventhal et al. 1999); cultured endothelial cells also secrete soluble factors that stimulate embryonic NSC self-renewal and increases the neuronal production of adult V-SVZ NSCs (Shen et al. 2004). Other in vitro studies show that microglial cells produce soluble factors important for V-SVZ neurogenesis but not self-renewal (Walton et al. 2006). Recent work suggests that direct cell-cell contact between B1 cells and endothelial cells is involved in maintenance of $\mathrm{B} 1$ cells quiescence and arrest in $\mathrm{G}_{0}-\mathrm{G}_{1}$ (Ottone et al. 2014). In the sections below, we discuss more advancements in our understanding of the molecular nature of such extrinsic niche factors from the variety of cell types founds in the adult V-SVZ.

\section{THE V-SVZ NEUROGENIC NICHE}

\section{Evidence from Transplantation Experiments}

For stem cells in general, self-renewal and progenitor cell differentiation are controlled by the specialized microenvironment, or "niche," in which these cells reside. This concept of a stem-cell niche originated from studies of blood cell development in which it was found that stem-cell fate can be modulated by soluble factors as well as membrane-bound molecules and extracellular matrix (ECM) (Schofield 1978). These soluble and nonsoluble niche signals may be derived from the stem cells themselves, their progenitors, and the neighboring cells (Watt and Hogan 2000; Fuchs et al. 2004). V-SVZ neurogenesis is in part determined by such niche signals, as initially evidenced by transplantation experiments. Mouse V-SVZcells grafted homotopically to another V-SVZ give rise to large numbers of $\mathrm{OB}$ interneurons for the recipient animal (Lois and Alvarez-Buylla 1994). In contrast, SVZ cells transplanted to nonneurogenic brain regions produce few, if any, neurons (Herrera et al. 1999). Purified postnatal V-SVZ neuroblasts also appear to give rise to only glial cells when transplanted to the nonneurogenic striatum, suggesting that even late lineage V-SVZ cells are dependent on local environmental cues to differentiate into or survive as neurons (Seidenfaden et al. 2006). Conversely, the V-SVZ niche appears to instruct appropriate neurogenesis of cultured progenitors from the hippocampus (Suhonen et al. 1996); this apparent NSC plasticity may relate to the relatively long duration ( $<2$ years) of in vitro culture before grafting. Although these transplantation experiments indicate that the V-SVZ contains local cues that can promote neurogenesis, as we describe in sections below, regional differences in the V-SVZ niche do not appear to be sufficient to determine the specific fate of the adult-born OB interneurons.

In addition to promoting neuronal differentiation, does the V-SVZ niche provide signals for NSC self-renewal? Although several molecular pathways have been implicated in having roles in V-SVZ NSC maintenance (as we discuss later), transplantation experiments demonstrating the existence of a V-SVZ niche for self-renewal are still lacking. It would be interesting to determine whether primary, uncultured V-SVZ cells can be serially grafted from one mouse V-SVZ to another and retain longterm self-renewal and $\mathrm{OB}$ interneuron production. It is, of course, possible that V-SVZ NSCs are not capable of satisfying this rigorous test of self-renewal. It would nevertheless be important to determine the difference between the V-SVZ neurogenic niche and nonneurogenic brain regions. Can nonneurogenic brain regions harbor grafted NSCs in a quiescent or slowly self-renewing state? Or, do nonneurogenic brain regions inexorably commit NSCs to terminally differentiated lineages?

\section{Mitogens and Growth Factors of the V-SVZ}

Fibroblast growth factor 2 (FGF-2) and epidermal growth factor (EGF) are the principal mitogens used to proliferate V-SVZ NSC in vitro, and it is likely that these growth factors (and/or 
signaling pathways) play roles in vivo (Fig. 3) Although it is not clear which V-SVZ cells express these mitogens in vivo, cultured cortical astrocytes express EGF and FGF-2 (Morita et al. 2005), suggesting that local astrocytes can provide these proliferative signals for the V-SVZ niche. EGF and FGF receptors (EGFRs and FGFRs) are expressed in the V-SVZ, and mice null for either FGF-2 (Zheng et al. 2004) or the EGFR ligand-transforming growth factor $\alpha$ (TGF- $\alpha$ ) (Tropepe et al. 1997) have significantly reduced V-SVZ neurogenesis. Although EGF and FGF are often thought of primarily as mitogens, they may also have roles in cell-fate control of V-SVZ cells and may even cause NSC dedifferentiation (Anderson 2001; Raff 2003).

Other growth factors have been implicated in regulation of the V-SVZ. Intraventricular infusion of ciliary neurotrophic factor (CNTF) (Emsley and Hagg 2003b) increases V-SVZ proliferation and may increase Notch1 expression (Chojnacki et al. 2003), suggesting a role in NSC self-renewal (see below discussion on Notch). Heparin-binding EGF (HB-EGF) also stimulates SVZ proliferation when administered into the ventricle (Jin et al. 2002a, 2003). Intraventricular infusion of BDNF has been reported to increase V-SVZ proliferation and $\mathrm{OB}$ neurogenesis (Zigova et al. 1998). Elevated levels of local BDNF expression have also been suggested to promote neurogenesis and migration into the underlying striatum (Pencea et al. 2001; Chmielnicki et al. 2004). However, another study infusing BDNF into the lateral ventricles did not reveal increased neurogenesis or production or migration into the striatum (Galvao et al. 2008). Platelet-derived growth factor (PDGF) signaling appears to play a role in balancing neuronal and oligodendrocyte production from the V-SVZ, and excessive PDGF signaling from ventricular infusion results in hyperplasia with some features of gliomas. Initial findings suggested that a significant subpopulation of cells within the hyperplasias is derived from type B1 cells (Jackson et al. 2006); however, more recent work suggests that the majority, if not all, PDGF-responsive cells are oligodendroglial progenitors within the V-SVZ (Chojnacki et al. 2011). Vascular en- dothelial growth factor (VEGF), a known angiogenic protein, also stimulates V-SVZ neurogenesis when infused into the ventricle (Jin et al. 2002b), suggesting a link between angiogenesis and neurogenesis (Palmer et al. 2000; Louissaint et al. 2002; Greenberg and Jin 2005).

There is evidence that some growth factors are derived from the local V-SVZ vascular plexus. Injection of tracer molecules into the peripheral bloodstream reveals "leakiness" of the vasculature where clusters of type B1 and C cells are found (Tavazoie et al. 2008). Given that PDGF is present at relatively high concentrations in blood serum, it is plausible that this growth factor and other blood-derived signals access the V-SVZ niche through this mechanism (Andreu-Agullo et al. 2009). Endothelial cells themselves also secrete factors that can regulate NSCs. Early experiments of endothelial cell coculture with embryonic NSCs indicated that endothelial-derived factors enhance the generation of neurospheres (Shen et al. 2004), which are spherical clusters of NSCs grown in suspension (Reynolds and Weiss 1992; Morshead et al. 1994). The chemokine stromal-derived factor 1 (SDF-1) is expressed by endothelial cells and ependymal cells, and the high levels of SDF-1 from endothelia recruit type $\mathrm{B} 1$ and $\mathrm{C}$ cells into the vascular plexus via chemotaxis (Kokovay et al. 2010). Pigment epithelium-derived factor (PEDF) is also secreted by endothelial and ependymal cells, and evidence suggests a role for this factor in type B1 cell maintenance (Ramirez-Castillejo et al. 2006). In vitro, PEDF enhances neurosphere self-renewal without affecting proliferation rate. Intraventricular infusion of PEDF activates the slowly-dividing type $\mathrm{B} 1$ cells, whereas infusion of a PEDF blocking reagent reduces type $\mathrm{B} 1$ cell proliferation. This activity of PEDF in V-SVZ NSCs involves Notch-dependent transcription (Andreu-Agullo et al. 2009), which we discuss in more detail later.

Endothelial cells also secrete neurotrophin3 (NT-3), and NT-3 signaling in V-SVZ NSCs causes the rapid phosphorylation of endothelial nitric oxide synthase (NOS), leading to the production of nitric oxide (NO), which acts as a cytostatic factor (Delgado et al. 2014). Thus, 
D.A. Lim and A. Alvarez-Buylla

these data indicate that endothelial cells also control adult V-SVZ neurogenesis at perhaps the earliest stage of the neuronal lineage, regulating the quiescence of the NSC population.

Betacellulin (BTC) is an EGF-like growth factor that is secreted by endothelial cells. Infusion of BTC in vivo increases V-SVZ cell proliferation and $\mathrm{OB}$ neurogenesis, and inhibition of BTC with neutralizing antibodies decreases the number of GLAST-positive cells and PSANCAM-positive neuroblasts (Gomez-Gaviro et al. 2012). Interestingly, BTC activates EGFR on type B1 and C cells as well as ErbB-4 receptors in neuroblasts, suggesting that BTC acts on both early and later stages of the V-SVZ neurogenic lineage.

Shh: A Type B1 Cell Maintenance Factor and Regulator of V-SVZ Regional Identity

$\mathrm{SHH}$ protein is both a classical morphogen in development and a mitogenic factor for a variety of neural precursors (Ruiz i Altaba et al. 2003). In the V-SVZ, it appears that SHH has multiple roles. Conditional deletion of Smoothened (Smo), an oxysterol-binding protein required for Shh signaling (Nachtergaele et al. 2013), in the early developing brain with the Nestin-Cre transgene results in dramatically decreased V-SVZ proliferation and OB neurogenesis (Machold et al. 2003). Furthermore, fewer neurospheres can be cultured from the Smo-deleted V-SVZ. Interestingly, Smo-deleted adult brains appear to be of normal size, suggesting that Shh signaling is not a prominent requirement for the proliferation of neural precursors during development. Alternatively, it is possible that the observation of postnatal and adult neurogenic defects in Smo-deleted brain primarily relates to the longer duration of Smo-deficiency in the V-SVZ NSC population; that is, perhaps the relatively rapid time course of mouse embryonic brain development ( $\sim 10$ days) is too short to reveal a defect related to Smo-deletion.

Cells responding to Shh signaling can be inferred by expression of the Gli1 transcription factor (Bai et al. 2002). Gli1-expressing cells are predominantly found in the ventral V-SVZ, and these exhibit NSC characteristics in vivo (Ma- chold et al. 2003; Palma et al. 2005; Ihrie et al. 2011). Treatment of Gli1-CreER;R26R mice with tamoxifen produces a cohort of LacZ-positive V-SVZ cells, and despite the elimination of rapidly dividing cells with the administration of an antimitotic, these mice continue to generate LacZ-positive $\mathrm{OB}$ interneurons over the next year (Ahn and Joyner 2005). These results indicate that Shh signaling is active in V-SVZ NSCs, but that this NSC population is relatively quiescent, as they are resistant to antimitotic treatment.

Although Smo is expressed in both dorsal and ventral V-SVZ type B1 cells, as indicated above, only ventral V-SVZ cells express high levels of Gli1. Shh mRNA is primarily detected in ventral forebrain neurons, suggesting that local expression of Shh activates Glil in the ventral VSVZ (Ihrie et al. 2011). However, it remains unclear how SHH reaches the V-SVZ. Conditional deletion of $S h h$ in adult mice reduces the production of ventrally derived OB interneurons, suggesting that Shh activity underlies type B1 cell regional heterogeneity. Dorsal V-SVZ cells appear to be resistant to Shh-pathway activation, suggesting that the regional identities of type B1 cells are epigenetically restricted. Interestingly, expression of an activated form of Smo (SmoM2) in dorsal V-SVZ progenitor cells results in their respecification; these SmoM2-expressing dorsal cells produce deep layer GC cells, similar to those produced by ventral V-SVZ progenitors. These observations suggest that different levels of Shh signaling underlie, at least in part, the regional specification of NSCs in the V-SVZ.

\section{BMP Signaling and Modulation by Their Antagonists}

Another family of neural morphogens, the BMPs also regulate adult brain germinal niches. BMP signaling promotes astrocyte differentiation of cultured embryonic neural precursors at the expense of oligodendrogliogenesis and neurogenesis (Gross et al. 1996). Adult V-SVZ cells produce BMPs and their receptors (Lim et al. 2000; Peretto et al. 2002). NOGGIN, a secreted $\mathrm{BMP}$ antagonist, is also locally expressed, most 
strongly in the ependymal cells. This locally derived BMP antagonist may contribute to the neurogenic niche for SVZ stem cells as it promotes neurogenesis both in vitro and in ectopic locations in vivo. Overexpression of BMP7 in the SVZ suppresses neurogenesis (Lim et al. 2000), and overexpression of Noggin from the ependyma suppresses local gliogenesis (Chmielnicki et al. 2004). Deletion of Smad4 - a downstream mediator from BMP signaling-in GLAST-positive V-SVZ cells impairs neurogenesis, suggesting that neuronal differentiation requires at least some level of Smad-mediated transcription (Colak et al. 2008). The lowdensity lipoprotein receptor-related protein 2 (LRP2) is expressed in V-SVZ ependymal cells, and LRP2 appears to act as an endocytic receptor for BMP4 (Gajera et al. 2010). Mice null for LRP2 have increased BMP signaling in the VSVZ, and neurogenesis is impaired. Hence, a "balance" between BMP and their antagonists may control the levels of neurogenesis and gliogenesis from NSCs in adult brain niches.

Like BMPs, leukemia inhibitory factor (LIF) induces GFAP-positive astrocyte differentiation from NSCs. Interestingly, BMP- and LIF-induced astrocytes from embryonic brain NSCs are distinct (Bonaguidi et al. 2005). Whereas BMP-induced GFAP-positive cells exit the cell cycle, take on a stellate morphology, and have limited NSC potential, LIF-induced GFAP ${ }^{+}$ cells have a bipolar/tripolar morphology, remain in the cell cycle, express progenitor cell markers, and behave as NSCs in culture. In embryonic stem cells, BMPs act in concert with LIF to sustain self-renewal and suppress differentiation (Ying et al. 2003). What is the effect of simultaneous BMP and LIF signaling on adult NSCs? It is possible that the ratio of BMP/LIF signaling on type B1 cells determines which is to serve as the niche cell and which is to be the stem cell. Reduction of BMP signaling by NOGGIN or other BMP antagonists may increase the LIF/BMP signaling ratio, increasing the likelihood that a V-SVZ astrocyte retains NSC characteristics. Consistent with this hypothesis, overexpression of LIF from an adenoviral vector injected into the brain ventricle promotes V-SVZ NSC self-renewal, expanding the population of NSCs in vivo while concomitantly decreasing $\mathrm{OB}$ neurogenesis (Bauer and Patterson 2006).

\section{Wnt Signaling in the V-SVZ}

In neural development, the Wnt family of secreted signaling molecules plays roles in stemcell maintenance, cellular proliferation, differentiation, migration, and axon guidance (Ille and Sommer 2005). In vitro studies have shown that WNT3A and WNT5A promote proliferation and neuronal differentiation of SVZ-derived NSC cultures (Yu et al. 2006), and transcripts for these factors have been identified in the V-SVZ and adult OB (Shimogori et al. 2004; Lim et al. 2006; Ramos et al. 2013). The canonical Wnt signaling pathway involves the binding of WNT to Frizzled $(\mathrm{Fz})$ receptors, which leads to stabilization of $\beta$-catenin protein, its nuclear translocation, and function as a transcriptional coactivator. Axin2 is a known target of the canonical Wnt signaling pathway, and Axin2 transcription is active in type B1, type $C$, but not type A cells (Adachi et al. 2007). Increased $\beta$ catenin by virally transduced expression of a stabilized form of this protein or inhibition of the GSK3b kinase, which is required for targeting $\beta$-catenin for degradation, increases the proliferation of Ascl1-expressing V-SVZ cells and OB neurogenesis. Noncanonical Wnt signaling also functions in the V-SVZ. Diversin encodes a component of both the canonical and noncanonical Wnt signaling pathways, and Diversin is expressed in type A cells (Ikeda et al. 2010). Overexpression of Diversin, but not a mutant form lacking a domain required for the noncanonical Wnt pathway, increases the proliferation of these neuroblasts. Thus, WNT proteins appear to be key extrinsic factors for V-SVZ neurogenesis, acting through both canonical and noncanonical pathways at distinct stages of the neurogenic lineage.

Membrane-Bound Signals of the Niche: Notch Signaling and Stem-Cell Maintenance

The Notch receptor is a large, single-pass transmembrane protein, and canonical Notch 
D.A. Lim and A. Alvarez-Buylla

signaling involves its activation at the cell surface by membrane-bound ligands expressed on neighboring cells. Ligand binding to the Notch receptor induces its proteolytic cleavage and the release of the Notch intracellular domain (NCID), which translocates to the nucleus, forms a complex with recombining binding protein suppressor of hairless (RBPJ), and activates specific gene expression (Ables et al. 2011). In NSCs, Notch signaling suppresses neuronal differentiation and maintains precursor cell properties (Gaiano and Fishell 2002). Notch1 and two cognate membrane-bound ligands, Jagged 1 and Delta1, are expressed in the adult V-SVZ (Stump et al. 2002; Nyfeler et al. 2005; Givogri et al. 2006). Retroviral induction of activated Notch (ActN) in the embryonic brain promotes radial glial identity and produces dense clusters of V-SVZ astrocytes postnatally (Gaiano et al. 2000). In postnatal V-SVZ cells, retrovirally transduced ActN prevents cell migration to the $\mathrm{OB}$, suppresses neuronal differentiation, and decreases proliferation, creating an apparently more "quiescent" cell type (Chambers et al. 2001). Conversely, inactivation of canonical Notch signaling via conditional deletion of Rbpj causes essentially all NSCs in the $\mathrm{V}-\mathrm{SVZ}$ to differentiate into type C and A cells, leading to the eventual depletion of NSCs from this adult region (Imayoshi et al. 2010). Thus, Notch signaling is likely a critical component of type B1 cell maintenance.

Numb and Numblike (Numbl) are mammalian homologs of Drosophila numb, a protein that antagonizes Notch function in one daughter cell during asymmetric precursor cell division (Roegiers and Jan 2004). In mice, Numb and Numbl are critical for embryonic neurogenesis (Johnson 2003). In the development of the postnatal V-SVZ, Numb/Numbl are required for the both ependymal wall integrity and neurogenesis (Kuo et al. 2006; Rasin et al. 2007).

The family of Hairy/enhancer of split (Hes) basic helix-loop-helix (bHLH) transcription factors include seven members, and Hes1 and Hes 5 are up-regulated by Notch signaling (Kageyama et al. 2005). Hes5 is expressed in adult SVZ along with the Notch receptor and cognate ligands (Stump et al. 2002). Misexpression of Hes1, Hes3, and Hes5 in embryonic brain inhibits neuronal differentiation and maintains the radial glial phenotype. Conversely, radial glial cells in Hes1, Hes5 double null mice prematurely differentiate into neurons. Furthermore, Hes 1;Hes5 null NSCs cannot be expanded in culture (Ishibashi et al. 1994; Ohtsuka et al. 1999, 2001). Of note, the premature differentiation of radial glia in Hes gene-deficient mice correlates with increased expression of proneural bHLH transcription factors including Ascl1 (Hatakeyama et al. 2004). HES1 directly represses Ascl1 transcription (Sasai et al. 1992; Chen et al. 1997). Interestingly, although Hes 1 represses Ascl1, ASCL1, which is expressed in type C cells, promotes the expression of Notch ligands (Kopan and Ilagan 2009). Indeed, Jagged 1 and Delta1 are expressed in type C and A cells (Givogri et al. 2006; Aguirre et al. 2010), which suggest a potential feedback regulation of the SVZ niche. Accumulation of newly born type A cells expressing Jagged1 or Delta1 may activate Notch signaling in type B1 cells, suppressing differentiation and potentiating selfrenewal. Intriguingly, Jagged 1 may be a downstream target from canonical Wnt signaling (Katoh 2006); it is thus possible that Wnt induces Jagged 1 expression in type C cells, which in turn activate Notch1 signaling in type B1 cells, maintaining this neurogenic pool in the V-SVZ.

\section{Role of Eph and Ephrins}

Eph receptors and their ephrin membranebound ligands may also control V-SVZ neurogenesis through a feedback mechanism (Holmberg et al. 2005). EphrinA2 is expressed by type $\mathrm{A}$ and $\mathrm{C}$ cells, and the EphA7 receptor is expressed in some type B1 and ependymal cells. EphA2-deficient mice have increased SVZ cell proliferation and $\mathrm{OB}$ neurogenesis; disruption of the interaction between ephrinA2 and EphA7 by infusion of blocking reagents also increases SVZ proliferation and $\mathrm{OB}$ neurogenesis. This data indicates that ephrinA2-EphA7 signaling normally inhibits SVZ proliferation. The investigators also provide data suggesting that this 
negative regulation of SVZ proliferation is mediated by reverse signaling through ephrinA2 in type $\mathrm{A}$ and $\mathrm{C}$ cells. That is, type B1 cells expressing EphA7 may normally inhibit the proliferation of type A and C cells via ephrinA2.

Several other Eph and ephrin family members are expressed and function in the adult V-SVZ (Liebl et al. 2003; Ricard et al. 2006; Furne et al. 2009). Infusion of EphB2-Fc fusion proteins disrupts SVZ cell migration and increases cell proliferation. Intriguingly, ventricle-contacting type B1 cells increase eightfold (Conover et al. 2000), suggesting that EphB2 and ephrinB2 participate in the maintenance of V-SVZ NSCs. Recent data also suggests that EphB2 acts downstream from Notch signaling and may regulate the conversion of some ependymal cells into astrocytes following local injury (Nomura et al. 2010). However, this result was mostly inferred from ependymal cell fate tracing with adenoviral vectors, which may infect other ventricle contacting cell types, such as type B1 cells.

Ottone and colleagues (2014) have recently suggested that contact with endothelial cells maintains quiescent NSCs and that this is mediated, at least in part, by eph/ephrinB2 signaling. In addition, this study also suggests that maintenance of NSC identity is mediated by Notch, via Jagged1 expression on endothelial cells. Interestingly, Jagged 1 has no effect on cyclin D levels. The investigators' in vitro work indicates that only a combination of eph and Notch signaling was sufficient to suppress differentiation and maintenance of $\mathrm{GFAP}^{+}$, Sox ${ }^{+}$in NSCs. Interestingly, in vivo cell-specific knockout of either ligand in endothelial cells induced an increase in B1 cell proliferation and in the number of migrating neuroblasts. Knockout of both ligands resulted in a greater increase in B1 cell activation than either knockout alone, suggesting that the EphrinB2 and Jagged 1 pathways act independently. This increase in B1-cell activation apparently results in an early depletion of the NSC in the VSVZ. The quiescence of B1 cells, therefore, appears to be controlled by eph and Notch signaling, and these two pathways appear to operate independently of each other.

\section{The Role of Neurotransmitters in the V-SVZ}

A number of different neurotransmitters play a role in the regulation of $\mathrm{V}-\mathrm{SVZ}$ neurogenesis. For instance, serotonin (5-HT) acts through receptors in the V-SVZ, regulating cell proliferation and $\mathrm{OB}$ neurogenesis (Brezun and Daszuta 1999; Banasr et al. 2004). Recent data indicates that most, if not all, 5-HT axons are supraependymal and form a dense plexus contacting both ependymal and type B1 cells (Tong et al. 2014a). These supraependymal 5-HT axons directly regulate neurogenesis from type B1 cells. In the postnatal V-SVZ, young neuroblasts spontaneously release $\gamma$-aminobutyric acid (GABA), activating $\mathrm{GABA}_{\mathrm{A}}$-receptors on precursor cells. This GABA-dependent depolarization of neural precursors inhibits cell proliferation and neuronal differentiation (Liu et al. 2005; Fernando et al. 2011). Thus, GABA may function in part as a negative-feedback signal derived from neuroblasts, down-regulating their own production. Interestingly, type B1 and C cells secrete the diazepam-binding inhibitor protein (DBI), which competitively inhibits GABA from binding to GABA receptors, increasing the proliferation and neurogenesis of the V-SVZ (Alfonso et al. 2012).

The role of dopamine in the SVZ niche is particularly interesting. The SVZ receives dopaminergic innervation from the midbrain, with type $\mathrm{C}$ cells being the predominant cell type expressing D2 receptors, and D3 receptors may also be involved in V-SVZ neurogenesis (Kim et al. 2010). Dopaminergic denervation results in decreased SVZ proliferation and $\mathrm{OB}$ neurogenesis and administration of the dopamine precursor levodopa could restore SVZ proliferation to near-normal levels (Hoglinger et al. 2004). The dopamine-induced activation of V-SVZ neurogenesis is in part mediated through EGF-dependent mechanisms (O'Keeffe et al. 2009).

A population of choline acetyltransferase $(\mathrm{ChAT})^{+}$neurons exists in the $\mathrm{V}-\mathrm{SVZ}$, and these $\mathrm{ChAT}^{+}$neurons are morphologically distinct from those of the striatum (Paez-Gonzalez et al. 2014). Optogenetic inhibition and stimulation of these neurons regulates neuroblast 
D.A. Lim and A. Alvarez-Buylla

production, and this effect of acetylcholine release on cell proliferation appears to be, in part, related to the activation of the FGF receptor.

$\mathrm{NO}$ is a free-radical signaling molecule produced by nitrergic neurons, which express the neuron-specific form of NOS; nitrergic neurons are found in close proximity to the SVZ. Both pharmacological inhibition and genetic disruption of NOS in nitregic neurons increases SVZ-OB neurogenesis, suggesting that $\mathrm{NO}$ also serves to restrict adult neurogenesis (Packer et al. 2003; Moreno-Lopez et al. 2004).

The above results indicate that germinal activity within the V-SVZ is influenced by multiple neural pathways that use different neurotransmitters. Some of these influences arise locally close to the V-SVZ, whereas others originate far away (e.g., the Raphe). It remains to be determined how and why V-SVZ progenitors integrate neural activity for the regulation of adult neurogenesis.

\section{The Remarkable Journey of Type A Cells}

After birth in the V-SVZ, type A cells migrate a considerable distance (up to several $\mathrm{mm}$ ) through a complex network of paths that converge as the RMS leads neuroblasts into the $\mathrm{OB}$. This journey is not only remarkable for the great distance but also for the highly directed nature of the migration. Type A cells appear to be actively guided rostrally, and very few appear to deviate from the restricted path into the $\mathrm{OB}$. By themselves, type A cells are imbued with an extensive migratory capacity. In vitro, type A cells form chains of themselves and migrate at relatively high speeds of $120 \mu \mathrm{m} / \mathrm{h}$ (Wichterle et al. 1997). These neuroblasts move in a stepwise manner, first extending a leading process with a growth cone, then translocating the cell body toward the growth cone tip; this process is repeated, leading to a "saltatory" cellular movement. Type A cells express both DCX, a microtubule-associated protein important for neuronal migration in the embryo (Francis et al. 1999) and collapsing-response mediator protein 4 (CRMP-4), which is involved in axon guidance (Nacher et al. 2000). Specific interactions between microtubules, myosin II, and cell adhesion are required for the nucleokinesis and the saltatory migration of V-SVZ neuroblasts (Schaar and McConnell 2005). In addition to playing a role in SVZ cell proliferation (see above), GABA also reduces the speed of neuroblast migration (Bolteus and Bordey 2004). The intracellular mechanism of how GABA regulates migratory speed is not known, but it appears to involve calcium signaling.

Specific cell-surface molecules on type A cells also confer migratory ability. For instance, type A cells express PSA-NCAM, and there is evidence that PSA and/or PSA-NCAM is critical for V-SVZ and RMS migration in postnatal mice (Tomasiewicz et al. 1993; Cremer et al. 1994; Ono et al. 1994; Hu et al. 1996) and is important for efficient chain migration in the adult (Chazal et al. 2000). Certain integrins (Jacques et al. 1998; Murase and Horwitz 2002; Emsley and Hagg 2003a) and ganglioside 9-Oacetyl GD3 (Miyakoshi et al. 2001), a glycolipid on type A cells, may also be required for chain migration. Tenascin- $C$ is among the several ECM molecules expressed in the RMS, and tenascin-C interacts with integrins (Yokosaki et al. 1996) as well as 9-O-acetyl GD3 (Probstmeier and Pesheva 1999); however, it is not known whether these particular interactions are essential for migration. Other ECM components of the RMS include chondroitin sulfate proteoglycans (Thomas et al. 1996) and laminin (Murase and Horwitz 2002). Infusion of a laminin peptide or laminin can redirect migration of type A cells to ectopic locations (Emsley and Hagg 2003a). Thus, the ECM of the migratory paths may create an environment permissive for neuroblast movement.

Perhaps one of the most intriguing processes that occurs in the V-SVZ is the directional migration of type A cells. What are the factors that guide the neuroblasts away from the SVZ, rostrally to the OB? SLIT-ROBO signaling appears to play a role. SLITs are expressed by the septum and choroid plexus, and the Robo-2/ Robo-3 receptors are expressed in the SVZ and RMS (Hu 1999; Li et al. 1999; Nguyen Ba-Charvet et al. 1999). SLIT proteins are chemorepulsive for type A cells in vitro ( $\mathrm{Hu} 1999$; Wu et al. 1999). A gradient of the SLIT2 chemorepulsive 
signal-with the highest concentration in the posterior SVZ — can be established by the flow of CSF, which parallels the directionality of type A cell migration. CSF flow is primarily driven by the ciliary beating of ependymal cells. Mice with defective ependymal cilia cannot establish this SLIT gradient and have impaired type A cell migration (Sawamoto et al. 2006). Thus, SLIT may function as a critical chemorepulsive factor for directional SVZ neuroblast migration, and the gradient of SLIT expression may require proper ependymal polarity, cilia, and CSF flow. Interestingly, Slit1 expression in migratory neuroblasts is also required to clear their migratory path of astrocytic processes (Kaneko et al. 2010).

The OB has also been suggested to be a source of chemoattractants for type A cells. Prokineticin-2 (Ng et al. 2005) and netrin-1 (Astic et al. 2002; Murase and Horwitz 2002) are both expressed in the $\mathrm{OB}$ and can attract type A cells in vitro. However, other groups have found that netrin-1 either has no activity or even repels type A cells (Mason et al. 2001; Liu and Rao 2003). In vitro, the $\mathrm{OB}$ does not attract SVZ neuroblasts (Hu et al. 1996), and surgical disconnection or removal of the $\mathrm{OB}$ does not prevent rostral migration (Jankovski et al. 1998; Kirschenbaum et al. 1999). Thus, although studies have identified molecules that can attract type A cells, the OB does not appear essential for their directional migration.

On reaching the OB, type A cells depart from the tangentially oriented RMS and migrate radially to different layers of the $\mathrm{OB}$. What are the molecular that mediate this change in mode of migration? Reelin, a protein critical for the laminar organization of cortex (Ogawa et al. 1995), is expressed in OB mitral cells and is necessary for the separation of type A cells from the tangentially oriented chains and the initiation of radial migration (Hack et al. 2002). Tenascin-R (Saghatelyan et al. 2004) and prokineticin-2 ( $\mathrm{Ng}$ et al. 2005) also induce detachment of type A cells from RMS chains. Additionally, these extracellular molecules also appear to attract radially migrating neuroblasts to appropriate OB layers. Interestingly, tenascin- $\mathrm{R}$ expression in the $\mathrm{OB}$ is reduced by odor deprivation, suggesting that neuron re- cruitment may be regulated by patterns of neuronal activity. The molecular determinants that guide type A cells to the appropriate OB layer remain largely unknown.

\section{CELL-INTRINSIC REGULATORS OF V-SVZ NEUROGENESIS}

The Importance of Cell-Intrinsic Factors for the Interpretation of Niche Signals

Based on the expression of certain cell-intrinsic factors, the same extracellular, extrinsic signal can be interpreted by a cell in vastly different ways. For instance, although BMPs induce glial differentiation of adult V-SVZ NSCs (see above) and E17-18 neural precursors (Gross et al. 1996), BMP signaling promotes neuronal and not glial differentiation of neural precursors from the E13-14 embryo (Li et al. 1998; Mabie et al. 1999). This may be related to the expression of high levels of the Neurogenin1 ( Ngn1) transcription factor by E13-14 neural precursors. Ngn1 not only activates genes for neuronal differentiation, it also sequesters the BMP downstream signaling factor SMAD1 from astrocyte differentiation genes. Interestingly, overexpression of $\mathrm{Ngn1}$ can convert BMP into a neuronal differentiation signal from a gliogenic signal (Sun et al. 2001). Along a similar line, in the adult SVZ cellular lineage, BMPs induce astrocyte differentiation in the early precursors while inducing cell-cycle exit and enhanced survival of late lineage neuroblasts (Lim et al. 2000; Coskun and Luskin 2002); this difference of BMP activity may be related to differential expression of BMP receptor subtypes at different stages of the V-SVZ neurogenic lineage (Lim et al. 2000; Panchision et al. 2001). These data illustrate the importance of cell-intrinsic factors in their ability of modify the effect of cell-extrinsic niche factors of the V-SVZ.

Transcription Factors and the Regulation of V-SVZ NSC Self-Renewal

SOX2 is a member of the SOX family of transcription factors that possess a high-mobilitygroup (HMG) domain for sequence-specific 
D.A. Lim and A. Alvarez-Buylla

DNA binding. SOX2 function can be modulated by its dimerization with other SOX family members, interactions with different transcriptional co-factors, and via a variety of posttranslational modifications (Sarkar and Hochedlinger 2013). In the V-SVZ, SOX2 is expressed in multiple cell types in this germinal region, including the type B1 cells (Ellis et al. 2004). Among many other neurological abnormalities, mice deficient for Sox2 (Ferri et al. 2004) have impaired adult V-SVZ neurogenesis. In V-SVZ NSCs, Sox2 expression requires Arsenite-resistance protein 2 (Ars2) (Andreu-Agullo et al. 2012). Ars2-deletion results in the loss of NSC self-renewal, and this defect can be rescued by Sox2 overexpression. Although orthologs of Ars2 are known for their conserved roles in miRNA biogenesis, Ars2 in mouse NSCs appears to function in a miRNA-independent manner. Instead, ARS2 is found to act as a transcription factor, binding to a specific region of a transcriptional enhancer required for Ars2-dependent Sox2 expression.

Prx 1 encodes a transcription factor of the homeobox gene family, and $\operatorname{Pr} x 1$ is coexpressed with Sox2 in type B1 cells (Shimozaki et al. 2013). PRX1 interacts with SOX2, and Prx1-deficient V-SVZ NSCs have defective self-renewal in vitro. Conversely, enforced $\operatorname{Pr} x 1$ in vivo results in increased numbers of undifferentiated precursor cells and decreased neuronal differentiation. Thus, although Sox 2 is expressed in various V-SVZ cell types, it is possible that PRX1 in type B1 cells serves as a SOX2 coactivator to specify NSC self-renewal. SOX2 also physically interacts with the TLX nuclear receptor, potentially regulating its transcriptional activity in V-SVZ NSCs (Shimozaki et al. 2012). Although both SOX2 and TLX bind the Tlx2 promoter, SOX2 positively regulates Tlx expression, whereas TLX normally represses its own expression. These cell culture studies suggest a Sox2-dependent mechanism for type B1 cell maintenance, in which SOX2 maintains Tlx expression via antagonism of a negative feedback loop of Tlx transcription.

Other homeobox genes may also have a role in V-SVZ NSC self-renewal. Empty spiracles homeobox 2 (Emx2) is expressed in the V-SVZ, and in vitro studies suggest that $E m \times 2$ regulates the frequency at which NSCs divide symmetrically (Galli et al. 2002). Ventral anterior homeobox 1 (Vaxl) is also strongly expressed in the V-SVZ and RMS, and Vaxl-null mice develop a much more disorganized V-SVZ with fewer GFAPpositive cells and defective $\mathrm{OB}$ neurogenesis (Soria et al. 2004). Given that Vax1-null mice do not develop ependyma, which are likely important niche cells, Vaxl could have a non-cellautonomous role in V-SVZ neurogenesis.

Inhibitor of DNA-binding (Id) genes encode dominant-negative antagonists of bHLH transcription factors, and high levels of $I d 1$ are found in type B1 cells, with lower levels in the type $\mathrm{C}$ cell transit-amplifying population (Nam and Benezra 2009). Although Id1-null or Id3null mice do not appear to have defects in the adult V-SVZ, conditional deletion of $I d 1, I d 2$, and Id3 (triple knockout) in Nestin-expressing neural precursors results in aberrant embryonic neural development owing to compromised NSC self-renewal (Niola et al. 2012). Acute loss of Id genes impairs NSC cell adhesion, and this defect relates to the derepression of Rap1GAP, the GTPase-activating protein for RAP1, which is a critical regulator of integrin signaling. Interestingly, in the V-SVZ of postnatal mice with $I d$ gene-deleted NSCs, there are threefold fewer GFAP-positive cells in close proximity to the laminin-positive endothelium. Knockdown of Rap1GAP in Id gene-deleted V-SVZ cells partially rescues their localization to the endothelia, suggesting that Id genes are required to maintain type B1 cells in close proximity with the vascular niche.

\section{Transcriptional Factors in V-SVZ Neuronal and Glial Lineage Commitment}

Type $C$ cells and a subset of type B1 cells express the basic helix-loop-helix (bHLH) transcription factor ASCL1 (Kohwi et al. 2005). Postnatal mice null for Ascl1 have impaired SVZ-OB neurogenesis and oligodendrogliogenesis, indicating its role in the specification of both neuronal and glial lineages (Parras et al. 2004). A subset of ASCL1-positive type $\mathrm{C}$ cells coexpress bHLH factor Neurogenin 2 (Ngn2), and the enforced expression of $\mathrm{Ngn} 2$ down-regulates Ascl1 
and induces the production of calretinin-positive OB neurons (Roybon et al. 2009). Another bHLH factor, Olig2, is also expressed in a subset of both type B1 cells and type C cells (Menn et al. 2006). Overexpression of Olig2 in V-SVZ cells represses the neuronal lineage while promoting oligodendrogliogenesis (Hack et al. 2005), and Olig2-deficency inhibits oligodendrocyte production (Marshall et al. 2005). Interestingly, in embryonic development, Olig2 alone also promotes oligodendrocyte development; however, when Ngn2 is coexpressed, Olig2 promotes motor neuron development (Mizuguchi et al. 2001; Novitch et al. 2001). Future studies may elucidate the mechanisms of this apparent molecular interplay between these bHLH transcription factors in V-SVZ lineage commitment.

Transcription Factors and the Generation of Diverse OB Interneuron Populations

The OB interneuron population is comprised of a variety of cellular phenotypes differing in their morphology, OB location, synaptic properties, and neurochemistry (Kosaka et al. 1995, 1998; Kosaka and Kosaka 2005; Parrish-Aungst et al. 2007). OB granule cells (GC) are located in the granule cell layer, and most of these neurons are GABAergic. PGCs are found more peripherally in the glomerular layer, and PGCs can be further subclassified based on the expression of calbindin, calretinin, glutamic acid decarboxylase (GAD), or TH (Fig. 1D). It has been suggested that a population of glutamatergic neurons are also born in the adult mouse (Brill et al. 2009), but this observation remains to be confirmed.

Mice null for $D l x 1 / 2$ homeobox transcription factors have severely impaired genesis of both GC and PGCs in development (Bulfone et al. 1998), and in the adult mouse, $D l x 1 / 2$ is expressed in $\mathrm{V}-\mathrm{SVZ}$ precursors that give rise to most $\mathrm{OB}$ interneuron subtypes (Batista-Brito et al. 2008). Ngn2 is expressed in a subpopulation of Ascl1-expressing cells, and Ngn2 appears to be followed by a cascade of transient expression of T-box brain 2 (Tbr2), bHLH gene Neurogenic differentiation 1 (Neurod1), and Tbr1.
Whether Ngn2, Tbr1, and Tbr2 are required for adult $\mathrm{OB}$ neurogenesis is still not known. However, Neurod 1 conditional deletion in Nestin-expressing neural precursors does indeed result in fewer OB neurons (Gao et al. 2009), and Neurod1 knockdown leads to defective OB neuron maturation (Boutin et al. 2010).

Increasing evidence indicate that cell-intrinsic transcriptional programs underlie the generation of the diverse populations of $\mathrm{OB}$ interneurons. First, it is clear that transcription factors are differentially expressed among the different $\mathrm{OB}$ neuron subtypes. For instance, Ets variant gene 1 (Etv1, also known as Er81) is expressed in dopaminergic cells and a subpopulation of calretinin-positive GCs. Meis homeobox 2 (Meis2) is expressed in dopaminergic and calbindin-positive GCs and a subpopulation of calretinin-positive PGCs (Allen et al. 2007). Second, lineage-tracing experiments indicate that even transient expression of specific transcription factors relates to distinct $\mathrm{OB}$ interneuron subtypes. Homeobox gene Emxl is expressed in cells that become calretinin-positive superficial GCs as well as PGC interneurons (Kohwi et al. 2007). Because Emx1 is expressed primarily in the developing pallium (and not the LGE, the presumed SVZ primordium), these data suggest that different embryonic anatomical regions contribute to different $\mathrm{OB}$ interneuron subtypes. Along these lines, a dorsal region of the V-SVZ contains neural precursors that transiently express $\mathrm{Ngn} 2$ and Tbr2 give rise to glutamatergic OB neurons (Brill et al. 2009). It remains to be determined whether Etv1, Meis2, Emx1, Ngn2, and Tbr2 are required to specify distinct $\mathrm{OB}$ neuron subtypes.

Increasing evidence also indicate a functional role for transcription factors in the generation of $\mathrm{OB}$ interneuron diversity. Homeobox gene Paired box 6 (Pax6) is expressed by a subpopulation of type $\mathrm{C}$ and A cells (Roybon et al. 2009), and Pax6 deficiency in cells in the V-SVZ results in fewer dopaminergic PGCs (Fig. 3) (Hack et al. 2005; Kohwi et al. 2005). Conversely, overexpression of Pax6 promotes the generation of dopaminergic neurons for the PGC. A subpopulation of nondopaminergic PGCs and GCs, on the other hand, appears to be, in part, 
D.A. Lim and A. Alvarez-Buylla

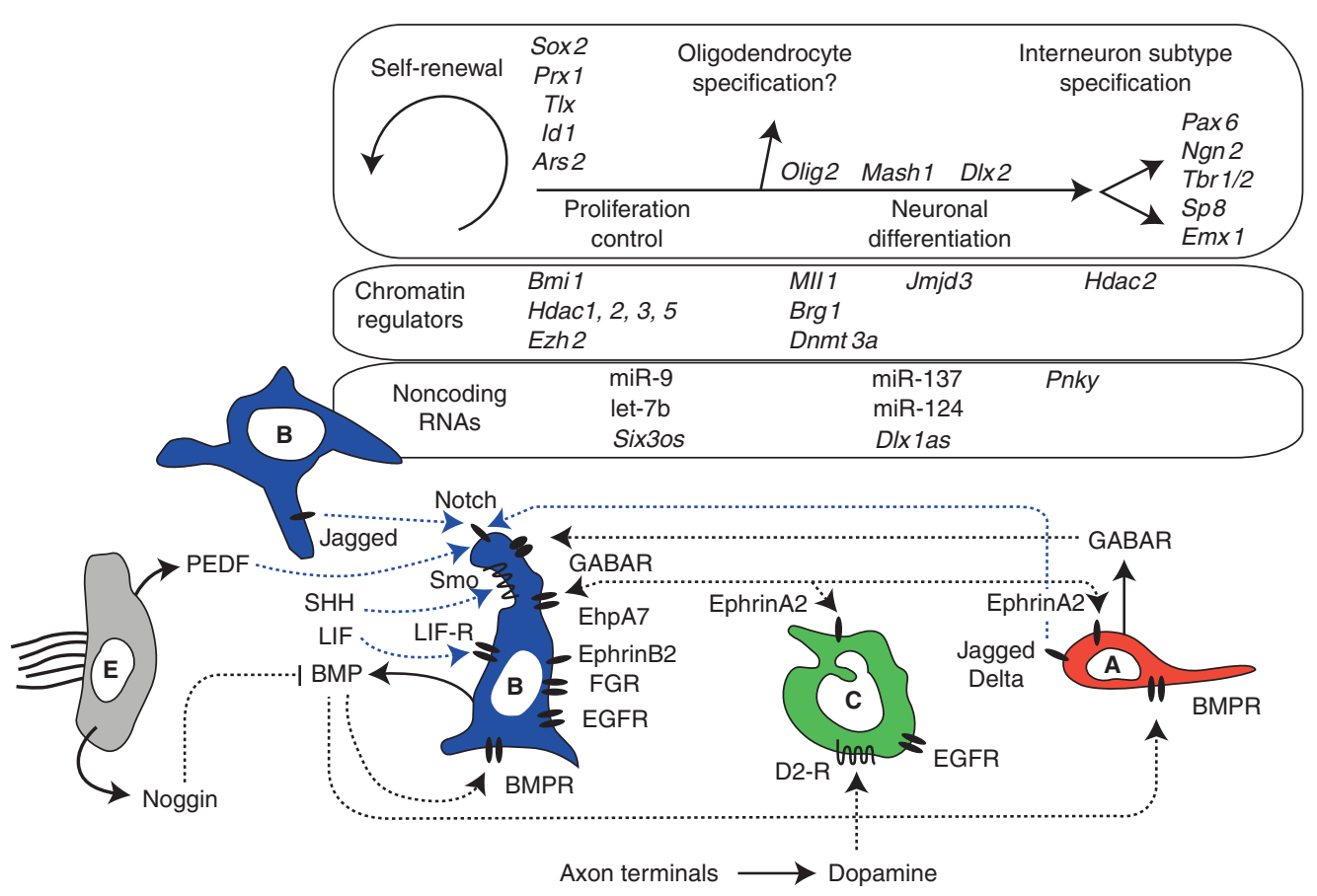

Figure 3. Interactions of selected ventricular-subventricular zone (V-SVZ) niche factors and cell-intrinsic regulators. Solid arrows indicate the cellular source of a secreted factor, when known. Dotted lines indicate molecular interactions, both known and hypothetical. Blue dotted lines show interactions that may promote SVZ NSC self-renewal. Select transcription factors that may be involved in self-renewal, proliferation control, and specification of different cell types are in italics in the top inset above. Select chromatin-regulators are in the inset second from the top. Select noncoding RNAs are in the third inset from the top (see text for details).

specified by the zinc-finger transcription factor Sp8 (Waclaw et al. 2006). Interestingly, neuroblasts null for $S p 8$ have increased Pax6 expression. One interpretation of this observation is that Sp8 normally represses Pax6 expression, shifting the $\mathrm{OB}$ interneuron fate from dopaminergic PGC to nondopaminergic interneurons. This notion is supported by the normal expression pattern of Pax6: there are many more Pax6expressing type A cells in the RMS than in the OB (Kohwi et al. 2005), suggesting that Pax6 becomes down-regulated in a subpopulation of neuroblasts that reach the OB.

As indicated above, $N k x 6.1$ and Zic family members are expressed in the anterioventral domain of the V-SVZ where four novel OB neuron subtypes are generated. The role of these transcription factors in the specification of these new types of $\mathrm{OB}$ interneurons remains unknown, but as discussed above, the V-SVZ can be viewed as a mosaic of distant NSCs that have inherited from the developing brain a unique combination of transcription factors. It is interesting how these domains, at different times in development or in the adult, end up generating very different types of neurons. Future combinatorial loss-of-function studies of these and other transcription factors will be required to further decipher the potential transcriptional "code" that determines distinct OB interneuron subtypes.

\section{Chromatin-Based Epigenetic Mechanisms in the V-SVZ}

Epigenetics is the study of biological mechanisms that regulate specific and heritable patterns of genome function without alterations to the DNA sequence. For long-term neurogenesis, type B1 cells must possess an enduring epi- 
genetic state that supports both self-renewal and the production of multiple, differentiated cell types. Conceptually, a stem-cell epigenetic state is likely to involve (1) active transcription of certain genes, (2) repression of other specific loci, and (3) transcriptional plasticity of genes required for lineage specification. A growing body of literature indicates that the structure and function of chromatin-the complex of genomic DNA with histone proteins - can underlie the epigenetic maintenance of genes in such "on," "off," and "poised" states.

The basic subunit of chromatin is the nucleosome, which is comprised of 146 base pairs of DNA wrapped approximately twice around an octamer of the four core histone proteins (H3, H4, H2A, and H2B). Chromatin states can be modified by: (1) noncovalent alterations to the protein-protein and protein-DNA interactions, and (2) covalent changes, such as DNA methylation and histone amino acid modifications (Kouzarides 2007). There are $>100$ different posttranslational histone modifications, and it is clear that some of these covalent changes correlate with gene expression. It is likely that such covalent modifications comprise a "histone code" that determines local chromatin structure and thus epigenetically imposes specific transcriptional states (Jenuwein and Allis 2001).

Noncovalent Chromatin-Remodeling Factors and V-SVZ Lineage Specification

Brama (Brm)-associated factor (BAF) chromatin-remodeling complexes use ATP hydrolysis to alter chromatin structure and play a critical role in transcriptional regulation. In mammals, BAF complexes consist of an ATPase subunit encoded by Brgl or Brm and up to 12 other BAF subunits (Ho and Crabtree 2010). Interestingly, the subunit composition of BAF complexes correlates with different stages of NSC development. For instance, whereas in proliferating embryonic NSCs BAF complexes contain BAF53A, during neuronal differentiation, BAF complexes instead contain BAF53B.

In cultured NSCs, PAX6 interacts with a number of BAF complex components, includ- ing BRG1 (Ninkovic et al. 2013). BRG1 is widely expressed in neurons and astrocytes of the adult brain, including cells in the V-SVZ. Conditional deletion of Brg1 in V-SVZ NSCs results in defective neurogenesis, and these Brg1-null precursors instead become primarily gliogenic. In the V-SVZ, Brg1-null precursors acquire ependymal cell characteristics, and the migratory cells are also converted into glial lineages. Most of the genes down-regulated in Brglnull V-SVZ cells contain PAX6-binding sites, and Pax6-deficency phenocopies the Brg1 deficency. Interestingly, enforced expression of PAX6 in Brg1-null cells does not rescue neurogenesis. These results suggest that PAX6 requires BRG1-containing BAF complexes for the activation of a neurogenic transcriptional program.

\section{Histone Acetylation}

Multiple lysine residues in the amino-terminal tails of core histones can be acetylated by histone acetyltransferases (HATs), and this covalent chromatin modification is associated with active transcription (Davie and Hendzel 1994). In contrast, histone deacetylation is associated with transcriptional repression, and this covalent change is catalyzed by four classes of histone deacetylases (HDACs): class I (HDAC1, 2, 3 , and 8), class II (HDAC 4, 5, 6, 9, and 10), class III (Sirt1-7), and class IV (HDAC11).

$\mathrm{V}-\mathrm{SVZ}$ neurospheres treated with class I and II HDAC inhibitors have increased neurogenesis and decreased oligodendrocyte production, suggesting a role for histone acetylation in neural fate determination (Siebzehnrubl et al. 2007). Class I and II HDAC inhibitors also increase the expression of cell-cycle inhibitors and block $G_{1}-S$ phase progression, implicating their role in NSC proliferation and self-renewal (Zhou et al. 2011). Furthermore, administration of class I/II HDAC inhibitors to postnatal mice strongly perturbs $\mathrm{V}-\mathrm{SVZ}$ neurogenesis (Foti et al. 2013).

In the postnatal V-SVZ, HDAC1 appears to be expressed in type $\mathrm{B} 1$ cells, and HDAC2 is expressed in type A cells (MacDonald and Roskams 2008; Montgomery et al. 2009; Foti et al. 2013). HDAC2 is also found in type C cells of 
the adult V-SVZ, suggesting a role for this enzyme in the transit amplifying stage of adult neurogenesis, and HDAC2 deletion targeted to V-SVZ NSCs results in defective neurogenesis (Jawerka et al. 2010).

HDAC3 and HDAC5 interact with the TLX transcription factor, which is expressed in type B1 and C cells (Sun et al. 2007). In cultured V-SVZ progenitors, TLX recruits both HDAC3 and HDAC5 to the promoters of cyclin-dependent kinase inhibitor $1 \mathrm{~A}$ (Cdkn1a, also known as p21Cip1/WAF1) and Pten, correlating with the repression of these cell-cycle regulators. Disruption of the interaction between TLX and HDAC5 with a TLX peptide results in increased Cdkn1a and Pten expression and reduced NSC proliferation, indicating the critical nature of the interaction between HDACs and a key transcription factor for V-SVZ neurogenesis.

\section{A Role for Noncanonical DNA Methylation in V-SVZ Neurogenesis}

DNA methyltransferases (DNMTs) catalyze the addition of methyl groups to cytosine residues. Although DNA methylation is well known for its repressive role at gene promoters, DNA methylation is also found in nonpromoter regions. DNMT1 is constitutively expressed in proliferating cells, and this enzyme symmetrically propagates methylation to the daughter strand during DNA replication. DNMT3A and DNMT3B are de novo methyltransferases, catalyzing cytosine methylation at new genomic locations (Law and Jacobsen 2010).

DNMT3A is prominently expressed in the V-SVZ and not in nonneurogenic brain regions (Wu et al. 2010). Interestingly, in the VSVZ, DNMT3A-dependent nonpromoter DNA methylation facilitates the transcription of key neurogenic genes (Wu et al. 2010). Dnmt3anull mice have reduced V-SVZ neurogenesis, and genome-wide analysis of DNA methylation and histone modifications indicate a novel mechanism of activation: DNMT3a methylates DNA proximal to the promoters of neurogenic genes (e.g., Dlx2), and this nonpromoter DNA methylation antagonizes the placement of repressive histone modifications.
Polycomb Group and Trithorax Group Chromatin-Modifying Factors: Regulators of V-SVZ Neurogenesis

The Polycomb group (PcG) and trithorax group (trxG) gene products were originally identified in Drosophila as developmental regulators that maintain the expression pattern of homeobox genes. PcG and trxG proteins assemble into large protein complexes that repress or activate transcription, respectively (van der Vlag and Otte 1999). Polycomb repressive complex 2 (PRC2) contains EZH2, a methyltransferase that catalyzes histone 3 lysine 27 trimethylation (H3K27me3). BMI1 and RING1B are components of the Polycomb repressive complex 1 (PRC1) that recognizes $\mathrm{H} 3 \mathrm{~K} 27 \mathrm{me} 3$ and mediates transcriptional silencing through multiple mechanisms, including chromatin compaction.

In the adult V-SVZ, Polycomb-mediated gene silencing is required for the maintenance of the NSC population (Molofsky et al. 2003, 2005, 2006; Fasano et al. 2009; He et al. 2009). In older mice, Bmi1-deficient V-SVZ cells generate fewer neurospheres, and overexpression of $B m i 1$ rescues this age-dependent defect, suggesting a role for polycomb in NSC self-renewal.

During postnatal development, EZH2 become restricted to adult NSCs and their daughter cells (Hwang et al. 2014). EZH2 expression thus appears to distinguish neurogenic astroglial cells from nonneurogenic astrocytes in the postnatal mouse and human brain. In mouse V-SVZ NSCs, EZH2 plays distinct and separable roles in the long-term production of new neurons for the $\mathrm{OB}$, regulating both self-renewal of NSCs via repression of Cdkn2a (Ink4a/Arf) and lineage specification through repression of developmental regulators including Olig2.

Genetic and molecular studies indicate that trxG complexes activate or maintain gene expression, antagonizing $\mathrm{PcG}$ repression. Mixed lineage leukemia-1 (Mll1) is the prototypic mammalian trxG homolog. Mll1 is expressed in the V-SVZ neurogenic lineage, and Mll1 deletion targeted to type $\mathrm{B} 1$ cells results in defective neurogenesis, but glial differentiation remains intact (Lim et al. 2009). In culture, Mll1deleted V-SVZ cells proliferate and maintain 
the expression of NSC markers. However, Mll1deleted SVZ cells are unable to properly activate $D l \times 2$ expression. The $D l \times 2$ promoter is a direct target of MLL1, and in Mll1-deleted cells, Dlx2 locus is enriched for $\mathrm{H} 3 \mathrm{~K} 27 \mathrm{me} 3$. MLL family members can physically interact with and recruit H3K27-specific demethylases UTX and JMDJ3 to specific loci (Swigut and Wysocka 2007). These data support a model in which MLL1 is required for the recruitment of an H3K27-specific demethylase to specific neurogenic loci.

Transcriptional enhancers can exist in a "poised" state, having enrichment of H3K27me3 (Rada-Iglesias et al. 2011), and in V-SVZ NSCs, the I12b enhancer of Dlx2 exhibits a poised chromatin signature (Park et al. 2014). With conditional deletion of Jmjd3, I12b remains enriched with $\mathrm{H} 3 \mathrm{~K} 27 \mathrm{me} 3$ in V-SVZ NSCs, and Dlx2-dependent neurogenesis fails. In Mll1-deleted cells, JMJD3 protein is not enriched at I12b, suggesting that MLL1 is required for the localization of JMJD3 at this important neurogenic enhancer. Although JMJD3 can interact with trxG proteins (De Santa et al. 2007), whether MLL1 directly recruits JMJD3 to such regulatory elements is still not known. Interestingly, JMJD3 is found at many thousands of neural enhancers in cells cultured from the embryonic mouse brain (Park et al. 2014), suggesting that this histone demethylase also regulates the function of enhancers during development.

How PcG and trxG factors are targeted to specific genetic loci in mammalian cells is not well understood, although some evidence suggests their recruitment via transcription factors and localization to specific $\mathrm{CpG}$ islands. More recently, various cell culture studies have shown the critical role of long noncoding RNAs (lncRNAs) in the targeting of these and other chromatin-modifying complexes.

LncRNAs and the Regulation of V-SVZ Neurogenesis

The mammalian genome transcribes many thousands of lncRNAs - transcripts $>200 \mathrm{nu}-$ cleotides long that have little evidence of protein coding potential. In addition to the well-known
IncRNA Xist - which is required for X chromosome inactivation via Polycomb-dependent mechanisms-many novel lncRNAs have been shown to interact with PcG and trxG chromatin-modifying factors to regulate cellular fate (Khalil et al. 2009; Bertani et al. 2011; Wang et al. 2011). For instance, lncRNA HOTAIR is required for targeting $\mathrm{PRC} 2$ and $\mathrm{H} 3 \mathrm{~K} 27 \mathrm{me} 3$ to specific genomic regions (Rinn and Chang 2012). lncRNAs also play a role in the targeting of MLL1. For instance, lncRNAs Mistral and HOTTIP both appear to target MLL1 complexes to specific HOX loci (Bertani et al. 2011; Wang et al. 2011). Given that $D l x$ bigene clusters are genetically linked to Hox clusters (e.g., $D l \times 1 / 2$ is on the same chromosome the HoxC cluster), and that Dlx and Hox genes are believed to have coevolved, it is tempting to speculate that lncRNAs are generally involved in the regulation of $D l x$ genes, as has been shown for the lncRNA Evf2 (Bond et al. 2009; Berghoff et al. 2013).

The lncRNA expression of the V-SVZ was characterized with complementary genomewide approaches including RNA-seq, RNACaptureSeq, ChIP-seq, and custom microarray analysis to associate lncRNAs with V-SVZ cell types and lineage specification (Ramos et al. 2013). Integration of these diverse approaches identified $\sim 100 \operatorname{lncRNAs}$ with potential roles in $\mathrm{V}$ SVZ neurogenesis, and knockdown of two such lncRNAs, Six3os and Dlxlas, showed their role in neuronal-glial lineage specification. Dlxlas is up-regulated during early stages of neurogenesis in vitro, and in vivo, its expression is highest in type C cells. In V-SVZ cultures, Dlxlas knockdown inhibits neuronal differentiation, but not gliogenesis. However, the function of this lncRNA in adult neurogenesis remains to be shown in vivo.

Pinky (Pnky) is a novel lncRNA that regulates the production of neurons from V-SVZ NSCs as well as NSCs in the developing mouse brain (Ramos et al. 2015). Pnky interacts with the PTBP1 splicing factor, and in V-SVZ NSCs, Pnky and PTPB1 regulate the splicing and expression of a set of transcripts that underlies the cellular phenotype. Taken together, these studies indicate that lncRNAs can serve critical regulatory functions in V-SVZ neurogenesis. 
D.A. Lim and A. Alvarez-Buylla

microRNAs: Modulators of V-SVZ Neurogenesis

microRNAs (miRNAs) are short (20-22 nucleotide) noncoding RNA transcripts that function as negative regulators of gene expression through messenger RNA degradation or translational inhibition. A number of specific miRNAs have been found to regulate V-SVZ NSCs self-renewal and neuronal differentiation via interaction with mRNAs that encode key transcriptional regulators. For instance, miR- 9 targets the Tlx transcript and appears to form a negative feedback mechanism for $T l x$ expression (Zhao et al. 2009). Although Tlx is highly expressed early in the neurogenic lineage, its expression is inversely correlated with miR-9 during differentiation. Furthermore, TLX is a transcriptional repressor for miR-9, suggesting that Tlx and miR-9 comprise a negative feedback loop that would enable a rapid transition from NSC to differentiated cell types. Tlx is also regulated by lethal-7b (let-7b), which is another miRNA that functions as a regulator of adult NSCs (Zhao et al. 2010). In addition to targeting $T l x$, let- $7 b$ also represses $C c n d 1$ (also known as cyclin D1) and Hmga2 (Nishino et al. 2008).

miR-137 is up-regulated in V-SVZ NSC monolayer cultures during neuronal differentiation (Silber et al. 2008). Overexpression of miR-137 in adult forebrain NSCs promotes their proliferation while decreasing neurogenesis (Szulwach et al. 2010). Conversely, miR-137 knockdown decreases proliferation and promotes neuronal differentiation. PRC2 factor Ezh2 is directly targeted by miR-137, indicating an interesting interplay between miRNAs and chromatin-based regulation of V-SVZ NSCs.

miR-124-the most abundant miRNA of the adult brain -is strongly up-regulated in differentiating V-SVZ NSCs (Silber et al. 2008). miR-124 promotes cell-cycle exit and neuronal differentiation in the V-SVZ (Cheng et al. 2009). Although knockdown of miR-124 maintains NSCs as proliferative precursors, miR-124 overexpression results in precocious neuronal differentiation. In V-SVZ cells, Sox9 is targeted by miR-124, and Sox9 down-regulation is required for neurogenesis, suggesting that the posttranscriptional regulation of Sox 9 by miR124 is an important aspect of adult neurogenesis. Interestingly, in embryonic brain NSCs, miR-124 (and miR-9) has been shown to be involved in the posttranscriptional regulation of Baf53a (Yoo et al. 2009), and expression of this BAF complex subunit is prominent in the V-SVZ transcriptome (Lim et al. 2006).

The Complex Interplay of Chromatin-Based Transcriptional Regulation and Cell-Intrinsic Factors

As discussed above, it is now clear that the longterm maintenance of V-SVZ neurogenesis involves a complex interplay between transcription factors, chromatin remodeling/modifying enzymes, and different classes of noncoding RNAs. For instance, TLX appears to function at early stages of the neurogenic lineage to maintain NSC self-renewal, and its regulatory function involves direct action of SOX2, HDACs, and feedback regulation by miRNAs. PAX6 directly binds and cooperates with active BAF complexes for neuronal differentiation, and certain PcG/trxG factors are required for V-SVZ neurogenesis. How PcG/trxG factors are targeted is poorly understood, but emerging evidence suggests that lncRNAs are involved in the localization of MLL and PRC2 complexes. The V-SVZ should continue to serve as an exciting model system in which to further explore such molecular interactions that regulate neural development. Given that adult NSCs possess many characteristics of their embryonic radial glial precursors, continued work in the V-SVZ is likely to reveal mechanistic themes relevant to embryonic and postnatal brain development, including that of humans.

\section{COMPARISON OF MOUSE AND HUMAN V-SVZ}

As the most extensive germinal niche of the adult mammalian brain, there is considerable interest in understanding whether the neonatal and adult human V-SVZ contains NSCs and long-range neuronal migration. Earlier studies revealed that small numbers of proliferating 
cells are found deep within the postnatal human V-SVZ (Eriksson et al. 1998; Sanai et al. 2004) and cells with properties of NSCs can be isolated from these walls (Sanai et al. 2004). However, histological examination of the V-SVZ in the adult human revealed a very different organization to the one observed in rodents. Very few cells with the morphology and marker expression (e.g., DCX) of migrating young neurons (type A cells) are observed. Instead, the human V-SVZ has a prominent gap layer (GAP), largely devoid of cells and populated by a dense network of interconnected processes from astrocytes and ependymal cells (Sanai et al. 2004; Quinones-Hinojosa et al. 2006). One layer deep to the GAP is a cellular "ribbon" containing astrocytes and their processes. It has been inferred that some of these astrocytes possess NSCs properties, but the paucity of intermediate progenitors and migrating cells suggests that the majority of these putative NSCs in the adult human brain are quiescent, and that migration from the V-SVZ of the lateral ventricles to the $\mathrm{OB}$, is rare, or nonexistent. Interestingly, prominent streams of DCX-positive migrating young neurons are observed in the gap area of the infant brain younger than 6 months of age (Sanai et al. 2011). In addition to an obvious RMS, the brain of young children has a medial migratory stream (MMS) connecting the V-SVZ with the medial prefrontal cortex. The abundance of DCX-positive cells in the GAP area in these young infants suggests that this is a major thoroughfare for tangential migration in early postnatal life, and that there are likely additional targets for these young neurons. Although there are very few young neurons in the GAP area of the adult human, recent studies suggest that precursor cells migrate into the striatum and differentiate into interneurons (Ernst et al. 2014). These new results regarding the potential of neurogenesis in the adult human striatum are still controversial, as other data indicate that all striatal interneurons in the adult human and monkey striatum are born during development (Wang et al. 2014).

Therefore, neurons continue to be incorporated into specific regions of the human brain well after birth; however, this process contracts during early childhood. Although the mechanisms of birth, migration, and neuronal recruitment in humans remain unknown, the expression of markers and the organization of these young migrating cells into chains suggests that human postnatal neurogenesis uses mechanisms similar to those found in rodents.

\section{CONCLUSION}

Significant progress has been made in our understanding of both the V-SVZ niche and cell-intrinsic molecular programs for stem-cell maintenance, progenitor cell-fate specification, migration, and terminal differentiation. In addition to harboring proliferative neural lineage cells (type B1, C, and A cells), the V-SVZ is also composed of other cell types (ependymal, microglial, and endothelial) that may serve as niche cells, producing factors important for long-term neurogenesis. The V-SVZ also receives afferents from local and distant neurons that may adjust neuronal and glia production according to information arising from neural activity in the adult brain. Here, we have reviewed some of this research progress.

We did not touch on one of the most intriguing questions of $\mathrm{V}-\mathrm{SVZ}$ and $\mathrm{OB}$ biology: What is the role of neurons born postnatally? Although most newly born $\mathrm{OB}$ interneurons initially become synaptically integrated into the OB (Belluzzi et al. 2003; Carleton et al. 2003 ), only $\sim 60 \%$ of adult-born OB interneurons survive for more than a month (Petreanu and Alvarez-Buylla 2002). How are these interneurons selected for survival, and what do the surviving neurons do? What are the "reasons" for adult OB neurogenesis? Lledo et al. (2006) review and speculate about some of these questions. Our pursuit to understand the molecular regulation of V-SVZ- OB neurogenesis may allow the engineering of precise methods to increasing or decreasing the production of specific subpopulations of $\mathrm{OB}$ interneurons. Such abilities would be powerful tools for investigating the function of adult V-SVZ- OB neurogenesis. Thus, the V-SVZ$\mathrm{OB}$ system is an appealing model in which to bridge a rapidly expanding cellular and mo- 
D.A. Lim and A. Alvarez-Buylla

lecular understanding of neurogenesis with emerging studies on the role of cellular plasticity in neural circuits.

Regarding the molecular understanding of neurogenesis, many soluble molecules and signaling pathways have been discovered to be critical for different aspects of $\mathrm{V}-\mathrm{SVZ}$ and OB biology, from NSC maintenance to directional migration. Nonsoluble, ECM components have also been implicated, especially for migration. We are now beginning to appreciate that the adult V-SVZ not only generates distinct cellular lineages (oligodendroglial and neuronal), but that the V-SVZ also retains a remarkable capacity to produce a great diversity of $\mathrm{OB}$ interneuron phenotypes. Distinct $\mathrm{OB}$ neuron subtypes relate to the regional identity of their type B1 cell precursor, and emerging data also suggest that a transcriptional factor combinatorial "code" is involved. The function of transcription factors in the V-SVZ is regulated by a complex interplay of chromatin remodeling/modifying factors and noncoding RNAs, and these can modify the effect of many cell extrinsic signals. Given that the human brain after birth also harbors a population of NSCs in the VSVZ, it is likely that biological principles discovered in the rodent V-SVZ will contribute to our understanding of postnatal human brain development. Furthermore, the detailed understanding of the molecular regulation of V-SVZ NSCs may inform strategies useful for the human NSC-based therapies.

\section{REFERENCES}

Ables JL, Breunig JJ, Eisch AJ, Rakic P. 2011. Not(ch) just development: Notch signalling in the adult brain. Nat Rev Neurosci 12: 269-283.

Adachi K, Mirzadeh Z, Sakaguchi M, Yamashita T, Nikolcheva T, Gotoh Y, Peltz G, Gong L, Kawase T, AlvarezBuylla A, et al. 2007. $\beta$-Catenin signaling promotes proliferation of progenitor cells in the adult mouse subventricular zone. Stem Cells 25: 2827-2836.

Aguirre A, Rubio ME, Gallo V. 2010. Notch and EGFR pathway interaction regulates neural stem cell number and self-renewal. Nature 467: 323-327.

Ahn S, Joyner AL. 2005. In vivo analysis of quiescent adult neural stem cells responding to Sonic hedgehog. Nature 437: 894-897.

Alfonso J, Le Magueresse C, Zuccotti A, Khodosevich K, Monyer H. 2012. Diazepam binding inhibitor promotes progenitor proliferation in the postnatal SVZ by reducing GABA signaling. Cell Stem Cell 10: 76-87.

Allen ZJ II, Waclaw RR, Colbert MC, Campbell K. 2007. Molecular identity of olfactory bulb interneurons: Transcriptional codes of periglomerular neuron subtypes. $J$ Mol Histol 38: 517-525.

Alonso M, Ortega-Perez I, Grubb MS, Bourgeois JP, Charneau P, Lledo PM. 2008. Turning astrocytes from the rostral migratory stream into neurons: A role for the olfactory sensory organ. J Neurosci 28: 11089-11102.

Alvarez-Buylla A, Lim DA. 2004. For the long run: Maintaining germinal niches in the adult brain. Neuron 41: 683-686.

Alvarez-Buylla A, Garcia-Verdugo JM, Mateo AS, Merchant-Larios H. 1998. Primary neural precursors and intermitotic nuclear migration in the ventricular zone of adult canaries. J Neurosci 18: 1020-1037.

Alvarez-Buylla A, Kohwi M, Nguyen TM, Merkle FT. 2008. The heterogeneity of adult neural stem cells and the emerging complexity of their niche. Cold Spring Harb Symp Quant Biol 73: 357-365.

Anderson DJ. 2001. Stem cells and pattern formation in the nervous system: The possible versus the actual. Neuron 30: $19-35$.

Andreu-Agullo C, Morante-Redolat JM, Delgado AC, Farinas I. 2009. Vascular niche factor PEDF modulates Notch-dependent stemness in the adult subependymal zone. Nat Neurosci 12: 1514-1523.

Andreu-Agullo C, Maurin T, Thompson CB, Lai EC. 2012. Ars2 maintains neural stem-cell identity through direct transcriptional activation of Sox2. Nature 481: 195-198.

Anthony TE, Klein C, Fishell G, Heintz N. 2004. Radial glia serve as neuronal progenitors in all regions of the central nervous system. Neuron 41: 881-890.

Astic L, Pellier-Monnin V, Saucier D, Charrier C, Mehlen P. 2002. Expression of netrin-1 and netrin-1 receptor, DCC, in the rat olfactory nerve pathway during development and axonal regeneration. Neuroscience 109: 643-656.

Bai CB, Auerbach W, Lee JS, Stephen D, Joyner AL. 2002. Gli2, but not Gli1, is required for initial Shh signaling and ectopic activation of the Shh pathway. Development 129: 4753-4761.

Banasr M, Hery M, Printemps R, Daszuta A. 2004. Serotonin-induced increases in adult cell proliferation and neurogenesis are mediated through different and common 5-HT receptor subtypes in the dentate gyrus and the subventricular zone. Neuropsychopharmacology 29: $450-460$.

Batista-Brito R, Close J, Machold R, Fishell G. 2008. The distinct temporal origins of olfactory bulb interneuron subtypes. J Neurosci 28: 3966-3975.

Bauer S, Patterson PH. 2006. Leukemia inhibitory factor promotes neural stem cell self-renewal in the adult brain. J Neurosci 26: 12089-12099.

Beckervordersandforth R, Tripathi P, Ninkovic J, Bayam E, Lepier A, Stempfhuber B, Kirchhoff F, Hirrlinger J, Haslinger A, Lie DC, et al. 2010. In vivo fate mapping and expression analysis reveals molecular hallmarks of prospectively isolated adult neural stem cells. Cell Stem Cell 7: 744-758. 
Belluzzi O, Benedusi M, Ackman J, LoTurco JJ. 2003. Electrophysiological differentiation of new neurons in the olfactory bulb. J Neurosci 23: 10411-10418.

Benner EJ, Luciano D, Jo R, Abdi K, Paez-Gonzalez P, Sheng H, Warner DS, Liu C, Eroglu C, Kuo CT. 2013. Protective astrogenesis from the SVZ niche after injury is controlled by Notch modulator Thbs4. Nature 497: 369-373.

Berghoff EG, Clark MF, Chen S, Cajigas I, Leib DE, Kohtz JD. 2013. Evf2 (Dlx6as) lncRNA regulates ultraconserved enhancer methylation and the differential transcriptional control of adjacent genes. Development 140: 4407-4416.

Bertani S, Sauer S, Bolotin E, Sauer F. 2011. The noncoding RNA Mistral activates Hoxa6 and Hoxa7 expression and stem cell differentiation by recruiting MLL1 to chromatin. Mol Cell 43: 1040-1046.

Bolteus AJ, Bordey A. 2004. GABA release and uptake regulate neuronal precursor migration in the postnatal subventricular zone. J Neurosci 24: 7623-7631.

Bonaguidi MA, McGuire T, Hu M, Kan L, Samanta J, Kessler JA. 2005. LIF and BMP signaling generate separate and discrete types of GFAP-expressing cells. Development 132: 5503-5514.

Bond AM, Vangompel MJ, Sametsky EA, Clark MF, Savage JC, Disterhoft JF, Kohtz JD. 2009. Balanced gene regulation by an embryonic brain ncRNA is critical for adult hippocampal GABA circuitry. Nat Neurosci 12: 10201027.

Boutin C, Hardt O, de Chevigny A, Core N, Goebbels S, Seidenfaden R, Bosio A, Cremer H. 2010. NeuroD1 induces terminal neuronal differentiation in olfactory neurogenesis. Proc Natl Acad Sci 107: 1201-1206.

Brezun JM, Daszuta A. 1999. Depletion in serotonin decreases neurogenesis in the dentate gyrus and the subventricular zone of adult rats. Neuroscience 89: 9991002.

Brill MS, Ninkovic J, Winpenny E, Hodge RD, Ozen I, Yang R, Lepier A, Gascon S, Erdelyi F, Szabo G, et al. 2009. Adult generation of glutamatergic olfactory bulb interneurons. Nat Neurosci 12: 1524-1533.

Bulfone A, Wang F, Hevner R, Anderson S, Cutforth T, Chen S, Meneses J, Pedersen R, Axel R, Rubenstein JL. 1998. An olfactory sensory map develops in the absence of normal projection neurons or GABAergic interneurons. Neuron 21: $1273-1282$.

Cabili MN, Trapnell C, Goff L, Koziol M, Tazon-Vega B, Regev A, Rinn JL. 2011. Integrative annotation of human large intergenic noncoding RNAs reveals global properties and specific subclasses. Genes Dev 25: 1915-1927.

Campbell K, Gotz M. 2002. Radial glia: Multi-purpose cells for vertebrate brain development. Trends Neurosci 25: 235-238.

Capela A, Temple S. 2002. LeX/ssea-1 is expressed by adult mouse CNS stem cells, identifying them as nonependymal. Neuron 35: 865-875.

Carleton A, Petreanu LT, Lansford R, Alvarez-Buylla A, Lledo PM. 2003. Becoming a new neuron in the adult olfactory bulb. Nat Neurosci 6: 507-518.

Chambers CB, Peng Y, Nguyen H, Gaiano N, Fishell G, Nye JS. 2001. Spatiotemporal selectivity of response to
Notch1 signals in mammalian forebrain precursors. Development 128: 689-702.

Chazal G, Durbec P, Jankovski A, Rougon G, Cremer H. 2000. Consequences of neural cell adhesion molecule deficiency on cell migration in the rostral migratory stream of the mouse. J Neurosci 20: 1446-1457.

Chen H, Thiagalingam A, Chopra H, Borges MW, Feder JN, Nelkin BD, Baylin SB, Ball DW. 1997. Conservation of the Drosophila lateral inhibition pathway in human lung cancer: A hairy-related protein (HES-1) directly represses achaete-scute homolog-1 expression. Proc Natl Acad Sci 94: 5355-5360.

Cheng LC, Pastrana E, Tavazoie M, Doetsch F. 2009. miR124 regulates adult neurogenesis in the subventricular zone stem cell niche. Nat Neurosci 12: 399-408.

Chmielnicki E, Benraiss A, Economides AN, Goldman SA. 2004. Adenovirally expressed noggin and brain-derived neurotrophic factor cooperate to induce new medium spiny neurons from resident progenitor cells in the adult striatal ventricular zone. J Neurosci 24: 21332142.

Chojnacki A, Shimazaki T, Gregg C, Weinmaster G, Weiss S. 2003. Glycoprotein 130 signaling regulates Notch1 expression and activation in the self-renewal of mammalian forebrain neural stem cells. J Neurosci 23: 1730-1741.

Chojnacki A, Mak G, Weiss S. 2011. PDGFR $\alpha$ expression distinguishes GFAP-expressing neural stem cells from PDGF-responsive neural precursors in the adult periventricular area. J Neurosci 31: 9503-9512.

Codega P, Silva-Vargas V, Paul A, Maldonado-Soto AR, Deleo AM, Pastrana E, Doetsch F. 2014. Prospective identification and purification of quiescent adult neural stem cells from their in vivo niche. Neuron 82: 545-559.

Colak D, Mori T, Brill MS, Pfeifer A, Falk S, Deng C, Monteiro R, Mummery C, Sommer L, Gotz M. 2008. Adult neurogenesis requires Smad4-mediated bone morphogenic protein signaling in stem cells. J Neurosci 28: 434-446.

Conover JC, Doetsch F, Garcia-Verdugo JM, Gale NW, Yancopoulos GD, Alvarez-Buylla A. 2000. Disruption of Eph/ephrin signaling affects migration and proliferation in the adult subventricular zone. Nat Neurosci 3: 10911097.

Coskun V, Luskin MB. 2002. Intrinsic and extrinsic regulation of the proliferation and differentiation of cells in the rodent rostral migratory stream. J Neurosci Res 69: 795802.

Coskun V, Wu H, Blanchi B, Tsao S, Kim K, Zhao J, Biancotti JC, Hutnick L, Krueger RC Jr, Fan G, et al. 2008. CD133 ${ }^{+}$ neural stem cells in the ependyma of mammalian postnatal forebrain. Proc Natl Acad Sci 105: 1026-1031.

Cremer H, Lange R, Christoph A, Plomann M, Vopper G, Roes J, Brown R, Baldwin S, Kraemer P, Scheff S, et al. 1994. Inactivation of the N-CAM gene in mice results in size reduction of the olfactory bulb and deficits in spatial learning. Nature 367: 455-459.

Davie JR, Hendzel MJ. 1994. Multiple functions of dynamic histone acetylation. J Cell Biochem 55: 98-105.

Delgado AC, Ferron SR, Vicente D, Porlan E, Perez-Villalba A, Trujillo CM, D'Ocon P, Farinas I. 2014. Endothelial NT-3 delivered by vasculature and CSF promotes quies- 
D.A. Lim and A. Alvarez-Buylla

cence of subependymal neural stem cells through nitric oxide induction. Neuron 83: 572-585.

De Santa F, Totaro MG, Prosperini E, Notarbartolo S, Testa G, Natoli G. 2007. The histone H3 lysine-27 demethylase Jmjd3 links inflammation to inhibition of polycombmediated gene silencing. Cell 130: 1083-1094.

Doetsch F, Alvarez-Buylla A. 1996. Network of tangential pathways for neuronal migration in adult mammalian brain. Proc Natl Acad Sci 93: 14895-14900.

Doetsch F, Garcia-Verdugo JM, Alvarez-Buylla A. 1997. Cellular composition and three-dimensional organization of the subventricular germinal zone in the adult mammalian brain. J Neurosci 17: 5046-5061.

Doetsch F, Caille I, Lim DA, Garcia-Verdugo JM, AlvarezBuylla A. 1999a. Subventricular zone astrocytes are neural stem cells in the adult mammalian brain. Cell 97: 703716.

Doetsch F, Garcia-Verdugo JM, Alvarez-Buylla A. 1999b. Regeneration of a germinal layer in the adult mammalian brain. Proc Natl Acad Sci 96: 11619-11624.

Doetsch F, Petreanu L, Caille I, Garcia-Verdugo JM, AlvarezBuylla A. 2002. EGF converts transit-amplifying neurogenic precursors in the adult brain into multipotent stem cells. Neuron 36: 1021-1034.

Ellis P, Fagan BM, Magness ST, Hutton S, Taranova O, Hayashi S, McMahon A, Rao M, Pevny L. 2004. SOX2, a persistent marker for multipotential neural stem cells derived from embryonic stem cells, the embryo or the adult. Dev Neurosci 26: 148-165.

Emsley JG, Hagg T. 2003a. $\alpha 6 \beta 1$ integrin directs migration of neuronal precursors in adult mouse forebrain. Exp Neurol 183: 273-285.

Emsley JG, Hagg T. 2003b. Endogenous and exogenous ciliary neurotrophic factor enhances forebrain neurogenesis in adult mice. Exp Neurol 183: 298-310.

Eriksson PS, Perfilieva E, Bjork-Eriksson T, Alborn AM, Nordborg C, Peterson DA, Gage FH. 1998. Neurogenesis in the adult human hippocampus. Nat Med 4: 13131317.

Ernst A, Alkass K, Bernard S, Salehpour M, Perl S, Tisdale J, Possnert G, Druid H, Frisen J. 2014. Neurogenesis in the striatum of the adult human brain. Cell 156: 1072-1083.

Fasano CA, Phoenix TN, Kokovay E, Lowry N, Elkabetz Y, Dimos JT, Lemischka IR, Studer L, Temple S. 2009. Bmi-1 cooperates with Foxg1 to maintain neural stem cell selfrenewal in the forebrain. Genes Dev 23: 561-574.

Fernando RN, Eleuteri B, Abdelhady S, Nussenzweig A, Andang M, Ernfors P. 2011. Cell cycle restriction by histone H2AX limits proliferation of adult neural stem cells. Proc Natl Acad Sci 108: 5837-5842.

Ferri AL, Cavallaro M, Braida D, Di Cristofano A, Canta A, Vezzani A, Ottolenghi S, Pandolfi PP, Sala M, DeBiasi S, et al. 2004. Sox2 deficiency causes neurodegeneration and impaired neurogenesis in the adult mouse brain. Development 131: 3805-3819.

Foti SB, Chou A, Moll AD, Roskams AJ. 2013. HDAC inhibitors dysregulate neural stem cell activity in the postnatal mouse brain. Int J Dev Neurosci 31: 434-447.

Francis F, Koulakoff A, Boucher D, Chafey P, Schaar B, Vinet MC, Friocourt G, McDonnell N, Reiner O, Kahn A, et al. 1999. Doublecortin is a developmentally regulated, mi- crotubule-associated protein expressed in migrating and differentiating neurons. Neuron 23: 247-256.

Fuchs E, Tumbar T, Guasch G. 2004. Socializing with the neighbors: Stem cells and their niche. Cell 116: 769-778.

Fuentealba LC, Obernier K, Alvarez-Buylla A. 2012. Adult neural stem cells bridge their niche. Cell Stem Cell 10: 698-708.

Fuentealba LC, Santiago BR, Parraguez JI, Obernier K, Romero R, Cepko CL, Alvarez-Buylla A. 2015. Embryonic origin of postnatal neural stem cells. Cell 161: 16441655.

Furne C, Ricard J, Cabrera JR, Pays L, Bethea JR, Mehlen P, Liebl DJ. 2009. EphrinB3 is an anti-apoptotic ligand that inhibits the dependence receptor functions of EphA4 receptors during adult neurogenesis. Biochim Biophys Acta 1793: 231-238.

Furutachi S, Miya H, Watanabe T, Kawai H, Yamasaki N, Harada Y, Imayoshi I, Nelson M, Nakayama KI, Hirabayashi Y, et al. 2015. Slowly dividing neural progenitors are an embryonic origin of adult neural stem cells. Nat Neurosci 18: 657-665.

Gaiano N, Fishell G. 2002. The role of notch in promoting glial and neural stem cell fates. Annu Rev Neurosci 25: $471-490$.

Gaiano N, Nye JS, Fishell G. 2000. Radial glial identity is promoted by Notch1 signaling in the murine forebrain. Neuron 26: 395-404.

Gajera CR, Emich H, Lioubinski O, Christ A, Beckervordersandforth-Bonk R, Yoshikawa K, Bachmann S, Christensen EI, Gotz M, Kempermann G, et al. 2010. LRP2 in ependymal cells regulates BMP signaling in the adult neurogenic niche. J Cell Sci 123: 1922-1930.

Galli R, Fiocco R, De Filippis L, Muzio L, Gritti A, Mercurio S, Broccoli V, Pellegrini M, Mallamaci A, Vescovi AL. 2002. Emx2 regulates the proliferation of stem cells of the adult mammalian central nervous system. Development 129: 1633-1644.

Galvao RP, Garcia-Verdugo JM, Alvarez-Buylla A. 2008. Brain-derived neurotrophic factor signaling does not stimulate subventricular zone neurogenesis in adult mice and rats. J Neurosci 28: 13368-13383.

Gao Z, Ure K, Ables JL, Lagace DC, Nave KA, Goebbels S, Eisch AJ, Hsieh J. 2009. Neurod1 is essential for the survival and maturation of adult-born neurons. Nat Neurosci 12: 1090-1092.

Garcia-Verdugo JM, Doetsch F, Wichterle H, Lim DA, Alvarez-Buylla A. 1998. Architecture and cell types of the adult subventricular zone: In search of the stem cells. $J$ Neurobiol 36: 234-248.

Givogri MI, de Planell M, Galbiati F, Superchi D, Gritti A, Vescovi A, de Vellis J, Bongarzone ER. 2006. Notch signaling in astrocytes and neuroblasts of the adult subventricular zone in health and after cortical injury. Dev Neurosci 28: 81-91.

Gomez-Gaviro MV, Scott CE, Sesay AK, Matheu A, Booth S, Galichet C, Lovell-Badge R. 2012. Betacellulin promotes cell proliferation in the neural stem cell niche and stimulates neurogenesis. Proc Natl Acad Sci 109: 1317-1322.

Greenberg DA, Jin K. 2005. From angiogenesis to neuropathology. Nature 438: 954-959. 
Gross RE, Mehler MF, Mabie PC, Zang Z, Santschi L, Kessler JA. 1996. Bone morphogenetic proteins promote astroglial lineage commitment by mammalian subventricular zone progenitor cells. Neuron 17: 595-606.

Hack I, Bancila M, Loulier K, Carroll P, Cremer H. 2002. Reelin is a detachment signal in tangential chain-migration during postnatal neurogenesis. Nat Neurosci 5: 939945.

Hack MA, Saghatelyan A, de Chevigny A, Pfeifer A, AsheryPadan R, Lledo PM, Gotz M. 2005. Neuronal fate determinants of adult olfactory bulb neurogenesis. Nat Neurosci 8: $865-872$.

Hatakeyama J, Bessho Y, Katoh K, Ookawara S, Fujioka M, Guillemot F, Kageyama R. 2004. Hes genes regulate size, shape and histogenesis of the nervous system by control of the timing of neural stem cell differentiation. Development 131: 5539-5550.

He S, Iwashita T, Buchstaller J, Molofsky AV, Thomas D, Morrison SJ. 2009. Bmi-1 over-expression in neural stem/progenitor cells increases proliferation and neurogenesis in culture but has little effect on these functions in vivo. Dev Biol 328: 257-272.

Herrera DG, Garcia-Verdugo JM, Alvarez-Buylla A. 1999. Adult-derived neural precursors transplanted into multiple regions in the adult brain. Ann Neurol 46: 867-877.

Ho L, Crabtree GR. 2010. Chromatin remodelling during development. Nature 463: 474-484.

Hoglinger GU, Rizk P, Muriel MP, Duyckaerts C, Oerte WH, Caille I, Hirsch EC. 2004. Dopamine depletion impairs precursor cell proliferation in Parkinson disease. Nat Neurosci 7: 726-735.

Holmberg J, Armulik A, Senti KA, Edoff K, Spalding K, Momma S, Cassidy R, Flanagan JG, Frisen J. 2005 Ephrin-A2 reverse signaling negatively regulates neural progenitor proliferation and neurogenesis. Genes Dev 19: $462-471$.

Hu H. 1999. Chemorepulsion of neuronal migration by Slit2 in the developing mammalian forebrain. Neuron 23: 703-711.

Hu H, Tomasiewicz H, Magnuson T, Rutishauser U. 1996. The role of polysialic acid in migration of olfactory bulb interneuron precursors in the subventricular zone. Neuron 16: 735-743.

Huang X, Liu J, Ketova T, Fleming JT, Grover VK, Cooper MK, Litingtung Y, Chiang C. 2010. Transventricular delivery of Sonic hedgehog is essential to cerebellar ventricular zone development. Proc Natl Acad Sci 107: 84228427.

Hwang WW, Salinas RD, Siu JJ, Kelley KW, Delgado RN, Paredes MF, Alvarez-Buylla A, Oldham MC, Lim DA. 2014. Distinct and separable roles for EZH2 in neurogenic astroglia. eLife 3: e02439.

Ihrie RA, Alvarez-Buylla A. 2011. Lake-front property: A unique germinal niche by the lateral ventricles of the adult brain. Neuron 70: 674-686.

Ihrie RA, Shah JK, Harwell CC, Levine JH, Guinto CD, Lezameta M, Kriegstein AR, Alvarez-Buylla A. 2011. Persistent sonic hedgehog signaling in adult brain determines neural stem cell positional identity. Neuron 71: $250-262$.
Ikeda M, Hirota Y, Sakaguchi M, Yamada O, Kida YS, Ogura T, Otsuka T, Okano H, Sawamoto K. 2010. Expression and proliferation-promoting role of Diversin in the neuronally committed precursor cells migrating in the adult mouse brain. Stem Cells 28: 2017-2026.

Ille F, Sommer L. 2005. Wnt signaling: Multiple functions in neural development. Cell Mol Life Sci 62: 1100-1108.

Imayoshi I, Sakamoto M, Yamaguchi M, Mori K, Kageyama R. 2010. Essential roles of Notch signaling in maintenance of neural stem cells in developing and adult brains. J Neurosci 30: 3489-3498.

Imura T, Nakano I, Kornblum HI, Sofroniew MV. 2006. Phenotypic and functional heterogeneity of GFAP-expressing cells in vitro: Differential expression of LeX/ CD15 by GFAP-expressing multipotent neural stem cells and non-neurogenic astrocytes. Glia 53: 277-293.

Ishibashi M, Moriyoshi K, Sasai Y, Shiota K, Nakanishi S, Kageyama R. 1994. Persistent expression of helix-loophelix factor HES-1 prevents mammalian neural differentiation in the central nervous system. EMBO J 13: 17991805.

Jackson EL, Garcia-Verdugo JM, Gil-Perotin S, Roy M, Quinones-Hinojosa A, VandenBerg S, Alvarez-Buylla A. 2006. PDGFR $\alpha$-positive B cells are neural stem cells in the adult SVZ that form glioma-like growths in response to increased PDGF signaling. Neuron 51: 187-199.

Jacques TS, Relvas JB, Nishimura S, Pytela R, Edwards GM, Streuli CH, ffrench-Constant C. 1998. Neural precursor cell chain migration and division are regulated through different $\beta 1$ integrins. Development 125: 3167-3177.

Jankovski A, Garcia C, Soriano E, Sotelo C. 1998. Proliferation, migration and differentiation of neuronal progenitor cells in the adult mouse subventricular zone surgically separated from its olfactory bulb. Eur J Neurosci 10: 3853-3868.

Jawerka M, Colak D, Dimou L, Spiller C, Lagger S, Montgomery RL, Olson EN, Wurst W, Gottlicher M, Gotz M. 2010. The specific role of histone deacetylase 2 in adult neurogenesis. Neuron Glia Biol 6: 93-107.

Jenuwein T, Allis CD. 2001. Translating the histone code. Science 293: 1074-1080.

Jin K, Mao XO, Sun Y, Xie L, Jin L, Nishi E, Klagsbrun M, Greenberg DA. 2002a. Heparin-binding epidermal growth factor-like growth factor: Hypoxia-inducible expression in vitro and stimulation of neurogenesis in vitro and in vivo. J Neurosci 22: 5365-5373.

Jin K, Zhu Y, Sun Y, Mao XO, Xie L, Greenberg DA. 2002b. Vascular endothelial growth factor (VEGF) stimulates neurogenesis in vitro and in vivo. Proc Natl Acad Sci 99: $11946-11950$.

Jin K, Xie L, Childs J, Sun Y, Mao XO, Logvinova A, Greenberg DA. 2003. Cerebral neurogenesis is induced by intranasal administration of growth factors. Ann Neurol 53: 405-409.

Johnson JE. 2003. Numb and Numblike control cell number during vertebrate neurogenesis. Trends Neurosci 26: 395 396.

Kageyama R, Ohtsuka T, Hatakeyama J, Ohsawa R. 2005. Roles of bHLH genes in neural stem cell differentiation. Exp Cell Res 306: 343-348. 
D.A. Lim and A. Alvarez-Buylla

Kaneko N, Marin O, Koike M, Hirota Y, Uchiyama Y, Wu JY, Lu Q, Tessier-Lavigne M, Alvarez-Buylla A, Okano H, et al. 2010. New neurons clear the path of astrocytic processes for their rapid migration in the adult brain. Neuron 67: 213-223.

Katoh M. 2006. Notch ligand, JAG1, is evolutionarily conserved target of canonical WNT signaling pathway in progenitor cells. Int J Mol Med 17: 681-685.

Khalil AM, Guttman M, Huarte M, Garber M, Raj A, Rivea Morales D, Thomas K, Presser A, Bernstein BE, van Oudenaarden A, et al. 2009. Many human large intergenic noncoding RNAs associate with chromatin-modifying complexes and affect gene expression. Proc Natl Acad Sci 106: $11667-11672$.

Kim Y, Wang WZ, Comte I, Pastrana E, Tran PB, Brown J, Miller RJ, Doetsch F, Molnar Z, Szele FG. 2010. Dopamine stimulation of postnatal murine subventricular zone neurogenesis via the D3 receptor. J Neurochem 114: $750-760$

Kirschenbaum B, Doetsch F, Lois C, Alvarez-Buylla A. 1999. Adult subventricular zone neuronal precursors continue to proliferate and migrate in the absence of the olfactory bulb. J Neurosci 19: 2171-2180.

Kohwi M, Osumi N, Rubenstein JL, Alvarez-Buylla A. 2005. Pax6 is required for making specific subpopulations of granule and periglomerular neurons in the olfactory bulb. J Neurosci 25: 6997-7003.

Kohwi M, Petryniak MA, Long JE, Ekker M, Obata K, Yanagawa Y, Rubenstein JL, Alvarez-Buylla A. 2007. A subpopulation of olfactory bulb GABAergic interneurons is derived from Emx1- and Dlx5/6-expressing progenitors. J Neurosci 27: 6878-6891.

Kokovay E, Goderie S, Wang Y, Lotz S, Lin G, Sun Y, Roysam B, Shen Q, Temple S. 2010. Adult SVZ lineage cells home to and leave the vascular niche via differential responses to SDF1/CXCR4 signaling. Cell Stem Cell 7: 163-173.

Kokovay E, Wang Y, Kusek G, Wurster R, Lederman P, Lowry N, Shen Q, Temple S. 2012. VCAM1 is essential to maintain the structure of the SVZ niche and acts as an environmental sensor to regulate SVZ lineage progression. Cell Stem Cell 11: 220-230.

Kopan R, Ilagan MX. 2009. The canonical Notch signaling pathway: Unfolding the activation mechanism. Cell 137: 216-233.

Kosaka T, Kosaka K. 2005. Structural organization of the glomerulus in the main olfactory bulb. Chem Senses 30: i107-i108.

Kosaka K, Aika Y, Toida K, Heizmann CW, Hunziker W, Jacobowitz DM, Nagatsu I, Streit P, Visser TJ, Kosaka T. 1995. Chemically defined neuron groups and their subpopulations in the glomerular layer of the rat main olfactory bulb. Neurosci Res 23: 73-88.

Kosaka K, Toida K, Aika Y, Kosaka T. 1998. How simple is the organization of the olfactory glomerulus?: The heterogeneity of so-called periglomerular cells. Neurosci Res 30: $101-110$.

Kouzarides T. 2007. Chromatin modifications and their function. Cell 128: 693-705.

Kriegstein A, Alvarez-Buylla A. 2009. The glial nature of embryonic and adult neural stem cells. Annu Rev Neurosci 32: $149-184$.
Kuo CT, Mirzadeh Z, Soriano-Navarro M, Rasin M, Wang D, Shen J, Sestan N, Garcia-Verdugo J, Alvarez-Buylla A, Jan LY, et al. 2006. Postnatal deletion of Numb/Numblike reveals repair and remodeling capacity in the subventricular neurogenic niche. Cell 127: 1253-1264.

Law JA, Jacobsen SE. 2010. Establishing, maintaining and modifying DNA methylation patterns in plants and animals. Nat Rev Genet 11: 204-220.

Lehtinen MK, Walsh CA. 2011. Neurogenesis at the braincerebrospinal fluid interface. Annu Rev Cell Dev Biol 27: 653-679.

Lehtinen MK, Zappaterra MW, Chen X, Yang YJ, Hill AD, Lun M, Maynard T, Gonzalez D, Kim S, Ye P, et al. 2011. The cerebrospinal fluid provides a proliferative niche for neural progenitor cells. Neuron 69: 893-905.

Leventhal C, Rafii S, Rafii D, Shahar A, Goldman SA. 1999. Endothelial trophic support of neuronal production and recruitment from the adult mammalian subependyma. Mol Cell Neurosci 13: 450-464.

Li W, Cogswell CA, LoTurco JJ. 1998. Neuronal differentiation of precursors in the neocortical ventricular zone is triggered by BMP. J Neurosci 18: $8853-8862$.

Li HS, Chen JH, Wu W, Fagaly T, Zhou L, Yuan W, Dupuis S, Jiang ZH, Nash W, Gick C, et al. 1999. Vertebrate slit, a secreted ligand for the transmembrane protein roundabout, is a repellent for olfactory bulb axons. Cell 96: 807-818.

Liebl DJ, Morris CJ, Henkemeyer M, Parada LF. 2003. mRNA expression of ephrins and Eph receptor tyrosine kinases in the neonatal and adult mouse central nervous system. J Neurosci Res 71: 7-22.

Lim DA, Tramontin AD, Trevejo JM, Herrera DG, GarciaVerdugo JM, Alvarez-Buylla A. 2000. Noggin antagonizes BMP signaling to create a niche for adult neurogenesis. Neuron 28: 713-726.

Lim DA, Suarez-Farinas M, Naef F, Hacker CR, Menn B, Takebayashi H, Magnasco M, Patil N, Alvarez-Buylla A. 2006. In vivo transcriptional profile analysis reveals RNA splicing and chromatin remodeling as prominent processes for adult neurogenesis. Mol Cell Neurosci 31: $131-148$.

Lim DA, Huang YC, Swigut T, Mirick AL, Garcia-Verdugo JM, Wysocka J, Ernst P, Alvarez-Buylla A. 2009. Chromatin remodelling factor Mll1 is essential for neurogenesis from postnatal neural stem cells. Nature 458: 529-533.

Liu G, Rao Y. 2003. Neuronal migration from the forebrain to the olfactory bulb requires a new attractant persistent in the olfactory bulb. J Neurosci 23: 6651-6659.

Liu X, Wang Q, Haydar TF, Bordey A. 2005. Nonsynaptic GABA signaling in postnatal subventricular zone controls proliferation of GFAP-expressing progenitors. Nat Neurosci 8: 1179-1187.

Lledo PM, Alonso M, Grubb MS. 2006. Adult neurogenesis and functional plasticity in neuronal circuits. Nat Rev 7: 179-193.

Lois C. 1996. Long distance neuronal migration in the adult mammalian brain. Rockefeller University, New York, p. 160.

Lois C, Alvarez-Buylla A. 1994. Long-distance neuronal migration in the adult mammalian brain. Science 264: $1145-1148$. 
Lois C, Garcia-Verdugo JM, Alvarez-Buylla A. 1996. Chain migration of neuronal precursors. Science 271: 978-981.

Louissaint A Jr, Rao S, Leventhal C, Goldman SA. 2002. Coordinated interaction of neurogenesis and angiogenesis in the adult songbird brain. Neuron 34: 945-960.

Mabie PC, Mehler MF, Kessler JA. 1999. Multiple roles of bone morphogenetic protein signaling in the regulation of cortical cell number and phenotype. J Neurosci 19: 7077-7088.

MacDonald JL, Roskams AJ. 2008. Histone deacetylases 1 and 2 are expressed at distinct stages of neuro-glial development. Dev Dyn 237: 2256-2267.

Machold R, Hayashi S, Rutlin M, Muzumdar MD, Nery S, Corbin JG, Gritli-Linde A, Dellovade T, Porter JA, Rubin $\mathrm{LL}$, et al. 2003. Sonic hedgehog is required for progenitor cell maintenance in telencephalic stem cell niches. Neuron 39: 937-950.

Marshall CA, Novitch BG, Goldman JE. 2005. Olig2 directs astrocyte and oligodendrocyte formation in postnatal subventricular zone cells. J Neurosci 25: 7289-7298.

Mason HA, Ito S, Corfas G. 2001. Extracellular signals that regulate the tangential migration of olfactory bulb neuronal precursors: Inducers, inhibitors, and repellents. $J$ Neurosci 21: 7654-7663.

Menn B, Garcia-Verdugo JM, Yaschine C, Gonzalez-Perez O, Rowitch D, Alvarez-Buylla A. 2006. Origin of oligodendrocytes in the subventricular zone of the adult brain. $J$ Neurosci 26: 7907-7918.

Mercier F, Kitasako JT, Hatton GI. 2002. Anatomy of the brain neurogenic zones revisited: Fractones and the fibroblast/macrophage network. J Comp Neurol 451: 170188.

Merkle FT, Tramontin AD, Garcia-Verdugo JM, AlvarezBuylla A. 2004. Radial glia give rise to adult neural stem cells in the subventricular zone. Proc Natl Acad Sci 101: $17528-17532$.

Merkle FT, Mirzadeh Z, Alvarez-Buylla A. 2007. Mosaic organization of neural stem cells in the adult brain. Science 317: 381-384.

Merkle FT, Fuentealba LC, Sanders TA, Magno L, Kessaris N, Alvarez-Buylla A. 2014. Adult neural stem cells in distinct microdomains generate previously unknown interneuron types. Nat Neurosci 17: 207-214.

Mich JK, Signer RA, Nakada D, Pineda A, Burgess RJ, Vue TY, Johnson JE, Morrison SJ. 2014. Prospective identification of functionally distinct stem cells and neurosphere-initiating cells in adult mouse forebrain. eLife 3: e02669.

Mirzadeh Z, Merkle FT, Soriano-Navarro M, Garcia-Verdugo JM, Alvarez-Buylla A. 2008. Neural stem cells confer unique pinwheel architecture to the ventricular surface in neurogenic regions of the adult brain. Cell Stem Cell 3: 265-278.

Mirzadeh Z, Doetsch F, Sawamoto K, Wichterle H, AlvarezBuylla A. 2010. The subventricular zone en-face: Wholemount staining and ependymal flow. J Vis Exp 6: 1938.

Miyakoshi LM, Mendez-Otero R, Hedin-Pereira C. 2001. The 9-O-acetyl GD3 gangliosides are expressed by migrating chains of subventricular zone neurons in vitro. Braz J Med Biol Res 34: 669-673.
Mizuguchi R, Sugimori M, Takebayashi H, Kosako H, Nagao M, Yoshida S, Nabeshima Y, Shimamura K, Nakafuku M. 2001. Combinatorial roles of olig2 and neurogenin2 in the coordinated induction of pan-neuronal and subtypespecific properties of motoneurons. Neuron 31: 757-771.

Molofsky AV, Pardal R, Iwashita T, Park IK, Clarke MF, Morrison SJ. 2003. Bmi-1 dependence distinguishes neural stem cell self-renewal from progenitor proliferation. $\mathrm{Na}$ ture 425: 962-967.

Molofsky AV, He S, Bydon M, Morrison SJ, Pardal R. 2005. $B m i-1$ promotes neural stem cell self-renewal and neural development but not mouse growth and survival by repressing the $\mathrm{p} 16^{\text {Ink4a }}$ and $\mathrm{p} 19^{\text {Arf }}$ senescence pathways. Genes Dev 19: 1432-1437.

Molofsky AV, Slutsky SG, Joseph NM, He S, Pardal R, Krishnamurthy J, Sharpless NE, Morrison SJ. 2006. Increasing p $16^{\mathrm{INK} 4 \mathrm{a}}$ expression decreases forebrain progenitors and neurogenesis during ageing. Nature 443: 448-452.

Montgomery RL, Hsieh J, Barbosa AC, Richardson JA, Olson EN. 2009. Histone deacetylases 1 and 2 control the progression of neural precursors to neurons during brain development. Proc Natl Acad Sci 106: 7876-7881.

Moreno-Lopez B, Romero-Grimaldi C, Noval JA, MurilloCarretero M, Matarredona ER, Estrada C. 2004. Nitric oxide is a physiological inhibitor of neurogenesis in the adult mouse subventricular zone and olfactory bulb. $J$ Neurosci 24: 85-95.

Morita M, Kozuka N, Itofusa R, Yukawa M, Kudo Y. 2005. Autocrine activation of EGF receptor promotes oscillation of glutamate-induced calcium increase in astrocytes cultured in rat cerebral cortex. J Neurochem 95: 871-879.

Morshead CM, Reynolds BA, Craig CG, McBurney MW, Staines WA, Morassutti D, Weiss S, van der Kooy D. 1994. Neural stem cells in the adult mammalian forebrain: A relatively quiescent subpopulation of subependymal cells. Neuron 13: 1071-1082.

Murase S, Horwitz AF. 2002. Deleted in colorectal carcino$\mathrm{ma}$ and differentially expressed integrins mediate the directional migration of neural precursors in the rostral migratory stream. J Neurosci 22: 3568-3579.

Nacher J, Rosell DR, McEwen BS. 2000. Widespread expression of rat collapsin response-mediated protein 4 in the telencephalon and other areas of the adult rat central nervous system. J Comp Neurol 424: 628-639.

Nachtergaele S, Whalen DM, Mydock LK, Zhao Z, Malinauskas T, Krishnan K, Ingham PW, Covey DF, Siebold C, Rohatgi R. 2013. Structure and function of the Smoothened extracellular domain in vertebrate Hedgehog signaling. eLife 2: $\mathrm{e} 01340$.

Nait-Oumesmar B, Decker L, Lachapelle F, Avellana-Adalid V, Bachelin C, Van Evercooren AB. 1999. Progenitor cells of the adult mouse subventricular zone proliferate, migrate and differentiate into oligodendrocytes after demyelination. Eur J Neurosci 11: 4357-4366.

Nam HS, Benezra R. 2009. High levels of Id1 expression define B1 type adult neural stem cells. Cell Stem Cell 5: 515-526.

Ng KL, Li JD, Cheng MY, Leslie FM, Lee AG, Zhou QY. 2005. Dependence of olfactory bulb neurogenesis on prokineticin 2 signaling. Science 308: 1923-1927.

Nguyen Ba-Charvet KT, Brose K, Marillat V, Kidd T, Goodman CS, Tessier-Lavigne M, Sotelo C, Chedotal A. 1999. 
D.A. Lim and A. Alvarez-Buylla

Slit2-mediated chemorepulsion and collapse of developing forebrain axons. Neuron 22: 463-473.

Ninkovic J, Steiner-Mezzadri A, Jawerka M, Akinci U, Masserdotti G, Petricca S, Fischer J, von Holst A, Beckers J, Lie CD, et al. 2013. The BAF complex interacts with Pax6 in adult neural progenitors to establish a neurogenic crossregulatory transcriptional network. Cell Stem Cell 13: 403-418.

Niola F, Zhao X, Singh D, Castano A, Sullivan R, Lauria M, Nam HS, Zhuang Y, Benezra R, Di Bernardo D, et al. 2012. Id proteins synchronize stemness and anchorage to the niche of neural stem cells. Nat Cell Biol 14: 477487.

Nishino J, Kim I, Chada K, Morrison SJ. 2008. Hmga2 promotes neural stem cell self-renewal in young but not old mice by reducing $16^{\text {Ink4a }}$ and $19^{\text {Arf }}$ expression. Cell 135: 227-239.

Noctor SC, Flint AC, Weissman TA, Dammerman RS, Kriegstein AR. 2001. Neurons derived from radial glial cells establish radial units in neocortex. Nature 409: 714-720.

Nomura T, Goritz C, Catchpole T, Henkemeyer M, Frisen J. 2010. EphB signaling controls lineage plasticity of adult neural stem cell niche cells. Cell Stem Cell 7: 730-743.

Novitch BG, Chen AI, Jessell TM. 2001. Coordinate regulation of motor neuron subtype identity and pan-neuronal properties by the bHLH repressor Olig2. Neuron 31: 773-789.

Nyfeler Y, Kirch RD, Mantei N, Leone DP, Radtke F, Suter U, Taylor V. 2005. Jagged1 signals in the postnatal subventricular zone are required for neural stem cell self-renewal. EMBO J 24: 3504-3515.

Ogawa M, Miyata T, Nakajima K, Yagyu K, Seike M, Ikenaka K, Yamamoto H, Mikoshiba K. 1995. The reeler geneassociated antigen on cajal-retzius neurons is a crucial molecule for laminar organization of cortical neurons. Neuron 14: 899-912.

Ohtsuka T, Ishibashi M, Gradwohl G, Nakanishi S, Guillemot F, Kageyama R. 1999. Hes1 and Hes5 as notch effectors in mammalian neuronal differentiation. EMBO J 18: 2196-2207.

Ohtsuka T, Sakamoto M, Guillemot F, Kageyama R. 2001 Roles of the basic helix-loop-helix genes Hes1 and Hes5 in expansion of neural stem cells of the developing brain. J Biol Chem 276: 30467-30474.

O’Keeffe GC, Tyers P, Aarsland D, Dalley JW, Barker RA, Caldwell MA. 2009. Dopamine-induced proliferation of adult neural precursor cells in the mammalian subventricular zone is mediated through EGF. Proc Natl Acad Sci 106: $8754-8759$.

Ono K, Tomasiewicz H, Magnuson T, Rutishauser U. 1994. $\mathrm{N}-\mathrm{CAM}$ mutation inhibits tangential neuronal migration and is phenocopied by enzymatic removal of polysialic acid. Neuron 13: 595-609.

Ortega F, Berninger B, Costa MR. 2013a. Primary culture and live imaging of adult neural stem cells and their progeny. Methods Mol Biol 1052: 1-11.

Ortega F, Gascon S, Masserdotti G, Deshpande A, Simon C, Fischer J, Dimou L, Chichung Lie D, Schroeder T, Berninger B. 2013b. Oligodendrogliogenic and neurogenic adult subependymal zone neural stem cells constitute distinct lineages and exhibit differential responsiveness to Wnt signalling. Nat Cell Biol 15: 602-613.

Ottone C, Krusche B, Whitby A, Clements M, Quadrato G, Pitulescu ME, Adams RH, Parrinello S. 2014. Direct cellcell contact with the vascular niche maintains quiescent neural stem cells. Nat Cell Biol 16: 1045-1056.

Packer MA, Stasiv Y, Benraiss A, Chmielnicki E, Grinberg A, Westphal H, Goldman SA, Enikolopov G. 2003. Nitric oxide negatively regulates mammalian adult neurogenesis. Proc Natl Acad Sci 100: 9566-9571.

Paez-Gonzalez P, Abdi K, Luciano D, Liu Y, Soriano-Navarro M, Rawlins E, Bennett V, Garcia-Verdugo JM, Kuo CT. 2011. Ank3-dependent SVZ niche assembly is required for the continued production of new neurons. Neuron 71: 61-75.

Paez-Gonzalez P, Asrican B, Rodriguez E, Kuo CT. 2014. Identification of distinct $\mathrm{ChAT}^{+}$neurons and activitydependent control of postnatal SVZ neurogenesis. Nat Neurosci 17: 934-942.

Palma V, Lim DA, Dahmane N, Sanchez P, Brionne TC, Herzberg CD, Gitton Y, Carleton A, Alvarez-Buylla A, Ruiz i Altaba A. 2005. Sonic hedgehog controls stem cell behavior in the postnatal and adult brain. Development 132: 335-344.

Palmer TD, Willhoite AR, Gage FH. 2000. Vascular niche for adult hippocampal neurogenesis. J Comp Neurol 425: 479-494.

Panchision DM, Pickel JM, Studer L, Lee SH, Turner PA, Hazel TG, McKay RDG. 2001. Sequential actions of BMP receptors control neural precursor cell production and fate. Gene Dev 15: 2094-2110.

Park DH, Hong SJ, Salinas RD, Liu SJ, Sun SW, Sgualdino J, Testa G, Matzuk MM, Iwamori N, Lim DA. 2014. Activation of neuronal gene expression by the JMJD3 demethylase is required for postnatal and adult brain neurogenesis. Cell Rep 8: 1290-1299.

Parras CM, Galli R, Britz O, Soares S, Galichet C, Battiste J, Johnson JE, Nakafuku M, Vescovi A, Guillemot F. 2004 Mash1 specifies neurons and oligodendrocytes in the postnatal brain. EMBO J 23: 4495-4505.

Parrish-Aungst S, Shipley MT, Erdelyi F, Szabo G, Puche AC. 2007. Quantitative analysis of neuronal diversity in the mouse olfactory bulb. J Comp Neurol 501: $825-836$.

Pastrana E, Cheng LC, Doetsch F. 2009. Simultaneous prospective purification of adult subventricular zone neural stem cells and their progeny. Proc Natl Acad Sci 106: 6387-6392.

Pencea V, Bingaman KD, Wiegand SJ, Luskin MB. 2001. Infusion of brain-derived neurotrophic factor into the lateral ventricle of the adult rat leads to new neurons in the parenchyma of the striatum, septum, thalamus, and hypothalamus. J Neurosci 21: 6706-6717.

Peretto P, Cummings D, Modena C, Behrens M, Venkatraman G, Fasolo A, Margolis FL. 2002. BMP mRNA and protein expression in the developing mouse olfactory system. J Comp Neurol 451: 267-278.

Petreanu L, Alvarez-Buylla A. 2002. Maturation and death of adult-born olfactory bulb granule neurons: Role of olfaction. J Neurosci 22: 6106-6113. 
Picard-Riera N, Decker L, Delarasse C, Goude K, Nait-Oumesmar B, Liblau R, Pham-Dinh D, Evercooren AB. 2002. Experimental autoimmune encephalomyelitis mobilizes neural progenitors from the subventricular zone to undergo oligodendrogenesis in adult mice. Proc Natl Acad Sci 99: 13211-13216.

Ponti G, Obernier K, Alvarez-Buylla A. 2013. Lineage progression from stem cells to new neurons in the adult brain ventricular-subventricular zone. Cell Cycle 12: 1649 1650.

Probstmeier R, Pesheva P. 1999. Tenascin-C inhibits $\beta_{1}$ integrin-dependent cell adhesion and neurite outgrowth on fibronectin by a disialoganglioside-mediated signaling mechanism. Glycobiology 9: 101-114.

Quinones-Hinojosa A, Sanai N, Soriano-Navarro M, Gonzalez-Perez O, Mirzadeh Z, Gil-Perotin S, Romero-Rodriguez R, Berger MS, Garcia-Verdugo JM, Alvarez-Buylla A. 2006. Cellular composition and cytoarchitecture of the adult human subventricular zone: A niche of neural stem cells. J Comp Neurol 494: 415-434.

Rada-Iglesias A, Bajpai R, Swigut T, Brugmann SA, Flynn RA, Wysocka J. 2011. A unique chromatin signature uncovers early developmental enhancers in humans. Nature 470: 279-283.

Raff M. 2003. Adult stem cell plasticity: Fact or artifact? Annu Rev Cell Dev Biol 19: 1-22.

Ramirez-Castillejo C, Sanchez-Sanchez F, Andreu-Agullo C, Ferron SR, Aroca-Aguilar JD, Sanchez P, Mira H, Escribano J, Farinas I. 2006. Pigment epithelium-derived factor is a niche signal for neural stem cell renewal. Nat Neurosci 9: 331-339.

Ramos AD, Diaz A, Nellore A, Delgado RN, Park KY, Gonzales-Roybal G, Oldham MC, Song JS, Lim DA. 2013. Integration of genome-wide approaches identifies lncRNAs of adult neural stem cells and their progeny in vivo. Cell Stem Cell 12: 616-628.

Ramos AD, Andersen RE, Liu SJ, Nowakowski TJ, Hong SJ, Gertz CC, Salinas RD, Zarabi H, Kriegstein AR, Lim DA. 2015. The long noncoding RNA Pnky regulates neuronal differentiation of embryonic and postnatal neural stem cells. Cell Stem Cell 16: 439-447.

Rasin MR, Gazula VR, Breunig JJ, Kwan KY, Johnson MB, Liu-Chen S, Li HS, Jan LY, Jan YN, Rakic P, et al. 2007. Numb and Numbl are required for maintenance of cadherin-based adhesion and polarity of neural progenitors. Nat Neurosci 10: 819-827.

Reynolds B, Weiss S. 1992. Generation of neurons and astrocytes from isolated cells of the adult mammalian central nervous system. Science 255: 1707-1710.

Ricard J, Salinas J, Garcia L, Liebl DJ. 2006. EphrinB3 regulates cell proliferation and survival in adult neurogenesis. Mol Cell Neurosci 31: 713-722.

Rinn JL, Chang HY. 2012. Genome regulation by long noncoding RNAs. Annu Rev Biochem 81: 145-166.

Roegiers F, Jan YN. 2004. Asymmetric cell division. Curr Opin Cell Biol 16: 195-205.

Roybon L, Deierborg T, Brundin P, Li JY. 2009. Involvement of Ngn2, Tbr and NeuroD proteins during postnatal ol factory bulb neurogenesis. Eur J Neurosci 29: 232-243.
Ruiz i Altaba A, Nguyen V, Palma V. 2003. The emergent design of the neural tube: Prepattern, SHH morphogen and GLI code. Curr Opin Genet Dev 13: 513-521.

Saghatelyan A, de Chevigny A, Schachner M, Lledo PM. 2004. Tenascin-R mediates activity-dependent recruitment of neuroblasts in the adult mouse forebrain. Nat Neurosci 7: 347-356.

Sanai N, Tramontin AD, Quinones-Hinojosa A, Barbaro NM, Gupta N, Kunwar S, Lawton MT, McDermott MW, Parsa AT, Manuel-Garcia Verdugo J, et al. 2004. Unique astrocyte ribbon in adult human brain contains neural stem cells but lacks chain migration. Nature 427: $740-744$.

Sanai N, Nguyen T, Ihrie RA, Mirzadeh Z, Tsai HH, Wong M, Gupta N, Berger MS, Huang E, Garcia-Verdugo JM, et al. 2011. Corridors of migrating neurons in the human brain and their decline during infancy. Nature 478: 382 386.

Sarkar A, Hochedlinger K. 2013. The Sox family of transcription factors: Versatile regulators of stem and progenitor cell fate. Cell Stem Cell 12: 15-30.

Sasai Y, Kageyama R, Tagawa Y, Shigemoto R, Nakanishi S. 1992. Two mammalian helix-loop-helix factors structurally related to Drosophila hairy and Enhancer of split. Genes Dev 6: 2620-2634.

Sawamoto K, Wichterle H, Gonzalez-Perez O, Cholfin JA, Yamada M, Spassky N, Murcia NS, Garcia-Verdugo JM, Marin O, Rubenstein JL, et al. 2006. New neurons follow the flow of cerebrospinal fluid in the adult brain. Science 311: 629-632.

Schaar BT, McConnell SK. 2005. Cytoskeletal coordination during neuronal migration. Proc Natl Acad Sci 102: 13652-13657.

Schofield R. 1978. The relationship between the spleen colony-forming cell and the haemopoietic stem cell. Blood Cells: 7-25.

Seidenfaden R, Desoeuvre A, Bosio A, Virard I, Cremer H. 2006. Glial conversion of SVZ-derived committed neuronal precursors after ectopic grafting into the adult brain. Mol Cell Neurosci 32: 187-198.

Shen Q, Goderie SK, Jin L, Karanth N, Sun Y, Abramova N, Vincent P, Pumiglia K, Temple S. 2004. Endothelial cells stimulate self-renewal and expand neurogenesis of neural stem cells. Science 304: 1338-1340.

Shen Q, Wang Y, Kokovay E, Lin G, Chuang SM, Goderie SK, Roysam B, Temple S. 2008. Adult SVZ stem cells lie in a vascular niche: A quantitative analysis of niche cell-cell interactions. Cell Stem Cell 3: 289-300.

Shi Y, Chichung Lie D, Taupin P, Nakashima K, Ray J, Yu RT, Gage FH, Evans RM. 2004. Expression and function of orphan nuclear receptor TLX in adult neural stem cells. Nature 427: 78-83.

Shimogori T, VanSant J, Paik E, Grove EA. 2004. Members of the $W n t, F z$, and $F r p$ gene families expressed in postnatal mouse cerebral cortex. J Comp Neurol 473: 496-510.

Shimozaki K, Zhang CL, Suh H, Denli AM, Evans RM, Gage FH. 2012. SRY-box-containing gene 2 regulation of nuclear receptor tailless $(T l x)$ transcription in adult neural stem cells. J Biol Chem 287: 5969-5978.

Shimozaki K, Clemenson GD Jr, Gage FH. 2013. Paired related homeobox protein 1 is a regulator of stemness 
D.A. Lim and A. Alvarez-Buylla

in adult neural stem/progenitor cells. J Neurosci 33: 4066-4075.

Siebzehnrubl FA, Buslei R, Eyupoglu IY, Seufert S, Hahnen E, Blumcke I. 2007. Histone deacetylase inhibitors increase neuronal differentiation in adult forebrain precursor cells. Exp Brain Res 176: 672-678.

Silber J, Lim DA, Petritsch C, Persson AI, Maunakea AK, Yu M, Vandenberg SR, Ginzinger DG, James CD, Costello JF, et al. 2008. miR-124 and miR-137 inhibit proliferation of glioblastoma multiforme cells and induce differentiation of brain tumor stem cells. BMC Med 6: 14 .

Soria JM, Taglialatela P, Gil-Perotin S, Galli R, Gritti A, Verdugo JM, Bertuzzi S. 2004. Defective postnatal neurogenesis and disorganization of the rostral migratory stream in absence of the Vax1 homeobox gene. J Neurosc 24: $11171-11181$.

Sotelo JR, Trujillo-Cenoz O. 1958. Electron microscope study on the development of ciliary components of the neural epithelium of the chick embryo. Z Zellforsch Mikrosk Anat 49: 1-12.

Stensaas LJ, Stensaas SS. 1968. Light microscopy of glial cells in turtles and birds. Z Zellforsch Mikrosk Anat 91: 315340.

Stump G, Durrer A, Klein AL, Lutolf S, Suter U, Taylor V. 2002. Notch1 and its ligands Delta-like and Jagged are expressed and active in distinct cell populations in the postnatal mouse brain. Mech Dev 114: 153-159.

Suhonen JO, Peterson DA, Ray J, Gage FH. 1996. Differentiation of adult hippocampus-derived progenitors into olfactory neurons in vivo. Nature 383: 624-627.

Sun Y, Nadal-Vicens M, Misono S, Lin MZ, Zubiaga A, Hua X, Fan G, Greenberg ME. 2001. Neurogenin promotes neurogenesis and inhibits glial differentiation by independent mechanisms. Cell 104: 365-376.

Sun G, Yu RT, Evans RM, Shi Y. 2007. Orphan nuclear receptor TLX recruits histone deacetylases to repress transcription and regulate neural stem cell proliferation. Proc Natl Acad Sci 104: 15282-15287.

Swigut T, Wysocka J. 2007. H3K27 demethylases, at long last. Cell 131: 29-32.

Szulwach KE, Li X, Smrt RD, Li Y, Luo Y, Lin L, Santistevan NJ, Li W, Zhao X, Jin P. 2010. Cross talk between microRNA and epigenetic regulation in adult neurogenesis. $J$ Cell Biol 189: 127-141.

Tavazoie M, Van der Veken L, Silva-Vargas V, Louissaint M, Colonna L, Zaidi B, Garcia-Verdugo JM, Doetsch F. 2008. A specialized vascular niche for adult neural stem cells. Cell Stem Cell 3: 279-288.

Thomas LB, Gates MA, Steindler DA. 1996. Young neurons from the adult subependymal zone proliferate and migrate along an astrocyte, extracellular matrix-rich pathway. Glia 17: 1-14.

Tomasiewicz H, Ono K, Yee D, Thompson C, Goridis C, Rutishauser U, Magnuson T. 1993. Genetic deletion of a neural cell adhesion molecule variant (N-CAM-180) produces distinct defects in the central nervous system. Neuron 11: 1163-1174.

Tong CK, Chen J, Cebrian-Silla A, Mirzadeh Z, Obernier K, Guinto CD, Tecott LH, Garcia-Verdugo JM, Kriegstein A, Alvarez-Buylla A. 2014a. Axonal control of the adult neural stem cell niche. Cell Stem Cell 14: 500-511.
Tong CK, Han YG, Shah JK, Obernier K, Guinto CD, Alvarez-Buylla A. 2014b. Primary cilia are required in a unique subpopulation of neural progenitors. Proc Natl Acad Sci 111: 12438-12443.

Tropepe V, Craig CG, Morshead CM, van der Kooy D. 1997. Transforming growth factor- $\alpha$ null and senescent mice show decreased neural progenitor cell proliferation in the forebrain subependyma. J Neurosci 17: 7850-7859.

van der Vlag J, Otte AP. 1999. Transcriptional repression mediated by the human polycomb-group protein EED involves histone deacetylation. Nat Genet 23: 474478.

Ventura RE, Goldman JE. 2007. Dorsal radial glia generate olfactory bulb interneurons in the postnatal murine brain. J Neurosci 27: 4297-4302.

Vergano-Vera E, Yusta-Boyo MJ, de Castro F, Bernad A, de Pablo F, Vicario-Abejon C. 2006. Generation of GABAergic and dopaminergic interneurons from endogenous embryonic olfactory bulb precursor cells. Development 133: $4367-4379$.

Waclaw RR, Allen ZJ 2nd, Bell SM, Erdelyi F, Szabo G, Potter SS, Campbell K. 2006. The zinc finger transcription factor Sp8 regulates the generation and diversity of olfactory bulb interneurons. Neuron 49: 503-516.

Walton NM, Sutter BM, Laywell ED, Levkoff LH, Kearns SM, Marshall GP II, Scheffler B, Steindler DA. 2006. Microglia instruct subventricular zone neurogenesis. Glia 54: 815-825.

Wang KC, Yang YW, Liu B, Sanyal A, Corces-Zimmerman R, Chen Y, Lajoie BR, Protacio A, Flynn RA, Gupta RA, et al. 2011. A long noncoding RNA maintains active chromatin to coordinate homeotic gene expression. Nature 472: $120-124$.

Wang C, You Y, Qi D, Zhou X, Wang L, Wei S, Zhang Z, Huang W, Liu Z, Liu F, et al. 2014. Human and monkey striatal interneurons are derived from the medial ganglionic eminence but not from the adult subventricular zone. J Neurosci 34: 10906-10923.

Watt FM, Hogan BL. 2000. Out of Eden: Stem cells and their niches. Science 287: 1427-1430.

Wichterle H, Garcia-Verdugo JM, Alvarez-Buylla A. 1997. Direct evidence for homotypic, glia-independent neuronal migration. Neuron 18: 779-791.

Wong SY, Reiter JF. 2008. The primary cilium at the crossroads of mammalian hedgehog signaling. Curr Topics Dev Biol 85: 225-260.

Wu W, Wong K, Chen J, Jiang Z, Dupuis S, Wu JY, Rao Y 1999. Directional guidance of neuronal migration in the olfactory system by the protein Slit. Nature 400: 331-336.

Wu H, Coskun V, Tao J, Xie W, Ge W, Yoshikawa K, Li E, Zhang Y, Sun YE. 2010. Dnmt3a-dependent nonpromoter DNA methylation facilitates transcription of neurogenic genes. Science 329: 444-448.

Ying QL, Nichols J, Chambers I, Smith A. 2003. BMP induction of Id proteins suppresses differentiation and sustains embryonic stem cell self-renewal in collaboration with STAT3. Cell 115: 281-292.

Yokosaki Y, Monis H, Chen J, Sheppard D. 1996. Differential effects of the integrins $\alpha 9 \beta 1, \alpha v \beta 3$, and $\alpha v \beta 6$ on cell proliferative responses to tenascin. Roles of the $\beta$ subunit 
extracellular and cytoplasmic domains. J Biol Chem 271: 24144-24150.

Yoo AS, Staahl BT, Chen L, Crabtree GR. 2009. MicroRNAmediated switching of chromatin-remodelling complexes in neural development. Nature 460: 642-646.

Yu JM, Kim JH, Song GS, Jung JS. 2006. Increase in proliferation and differentiation of neural progenitor cells isolated from postnatal and adult mice brain by Wnt-3a and Wnt-5a. Mol Cell Biochem 288: 17-28.

Zhao C, Sun G, Li S, Shi Y. 2009. A feedback regulatory loop involving microRNA-9 and nuclear receptor TLX in neural stem cell fate determination. Nat Struct Mol Biol 16: 365-371.

Zhao C, Sun G, Li S, Lang MF, Yang S, Li W, Shi Y. 2010 MicroRNA let-7b regulates neural stem cell proliferation and differentiation by targeting nuclear receptor TLX signaling. Proc Natl Acad Sci 107: 1876-1881.

Zheng W, Nowakowski RS, Vaccarino FM. 2004. Fibroblast growth factor 2 is required for maintaining the neural stem cell pool in the mouse brain subventricular zone. Dev Neurosci 26: 181-196.

Zhou Q, Dalgard CL, Wynder C, Doughty ML. 2011. Histone deacetylase inhibitors SAHA and sodium butyrate block $\mathrm{G}_{1}$-to-S cell cycle progression in neurosphere formation by adult subventricular cells. BMC Neurosci 12: 50.

Zigova T, Pencea V, Wiegand SJ, Luskin MB. 1998. Intraventricular administration of BDNF increases the number of newly generated neurons in the adult olfactory bulb. Mol Cell Neurosci 11: 234-245. 


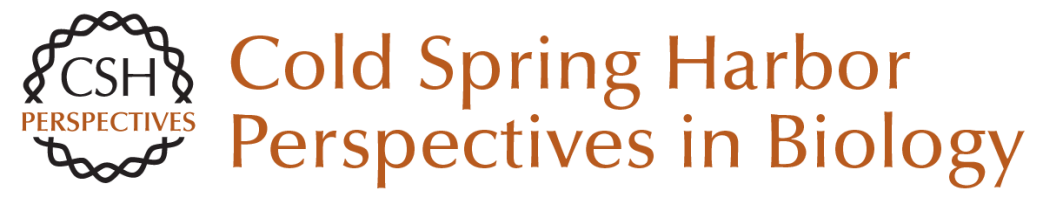

\section{The Adult Ventricular-Subventricular Zone (V-SVZ) and Olfactory Bulb (OB) Neurogenesis}

Daniel A. Lim and Arturo Alvarez-Buylla

Cold Spring Harb Perspect Biol 2016; doi: 10.1101/cshperspect.a018820 originally published online April 5, 2016

\section{Subject Collection Neurogenesis}

Adult Neurogenesis and Psychiatric Disorders Eunchai Kang, Zhexing Wen, Hongjun Song, et al.

Neuronal Circuitry Mechanisms Regulating Adult Mammalian Neurogenesis Juan Song, Reid H.J. Olsen, Jiaqi Sun, et al.

Neurogenesis in the Developing and Adult Brain --Similarities and Key Differences Magdalena Götz, Masato Nakafuku and David Petrik

Genetics and Epigenetics in Adult Neurogenesis Jenny Hsieh and Xinyu Zhao

The Adult Ventricular-Subventricular Zone (V-SVZ) and Olfactory Bulb (OB) Neurogenesis Daniel A. Lim and Arturo Alvarez-Buylla

Diversity of Neural Precursors in the Adult Mammalian Brain Michael A. Bonaguidi, Ryan P. Stadel, Daniel A. Berg, et al.

Detection and Phenotypic Characterization of Adult Neurogenesis

H. Georg Kuhn, Amelia J. Eisch, Kirsty Spalding, et al.

Maturation and Functional Integration of New Granule Cells into the Adult Hippocampus Nicolas Toni and Alejandro F. Schinder
Adult Olfactory Bulb Neurogenesis

Pierre-Marie Lledo and Matt Valley

Adult Neurogenesis in Fish Julia Ganz and Michael Brand

In Vitro Models for Neurogenesis Hassan Azari and Brent A. Reynolds Engineering of Adult Neurogenesis and
Gliogenesis

Benedikt Berninger and Sebastian Jessberger

Computational Modeling of Adult Neurogenesis James B. Aimone

Control of Adult Neurogenesis by Short-Range

Morphogenic-Signaling Molecules Youngshik Choe, Samuel J. Pleasure and Helena Mira

Adult Neurogenesis: An Evolutionary Perspective Gerd Kempermann

Epilepsy and Adult Neurogenesis

Sebastian Jessberger and Jack M. Parent

For additional articles in this collection, see http://cshperspectives.cshlp.org/cgi/collection/

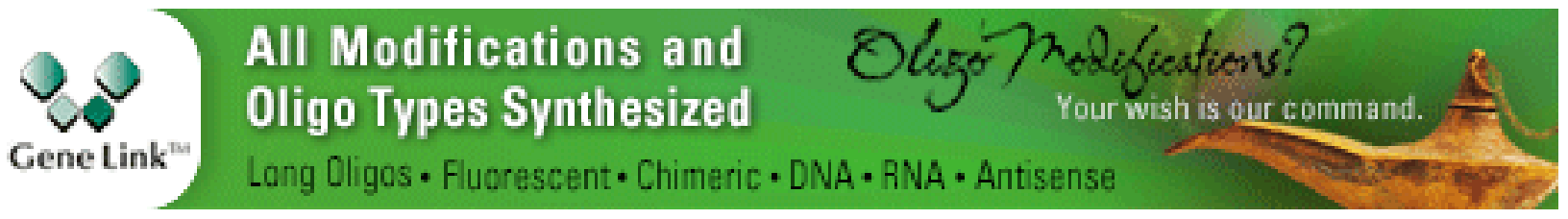


For additional articles in this collection, see http://cshperspectives.cshlp.org/cgi/collection/

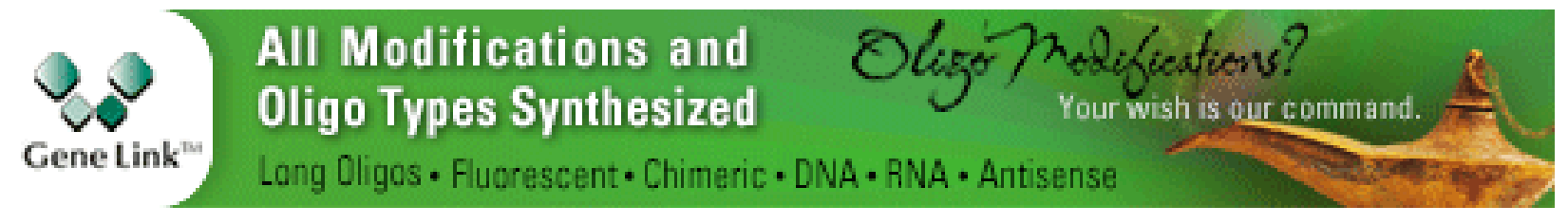

Copyright @ 2016 Cold Spring Harbor Laboratory Press; all rights reserved 